\title{
Ciclos econômicos e a composição da pobreza no Brasil: uma análise para as décadas recentes *
}

\author{
Ricardo Agostini Martini ${ }^{* *}$ \\ Ana Maria Hermeto *** \\ Frederico G. Jayme Jr. ${ }^{* * * *}$
}

\begin{abstract}
Resumo
O presente trabalho busca estudar e analisar o impacto dos ciclos macroeconômicos sobre a composição da pobreza na economia brasileira contemporânea (1987-2005). Mais especificamente, procura-se obter respostas para três questões: primeiro, quais são os grupos demográficos que mais sofrem as fases recessivas dos ciclos; segundo, se o crescimento econômico é suficiente para beneficiar todos os grupos mais associados à pobreza; terceiro, quais políticas macroeconômicas estão mais associadas à pobreza e a sua amenização. O trabalho utilizou uma interação de microdados da PNAD com dados macroeconômicos de fontes como o IPEA-DATA, o Banco Central do Brasil e a Secretaria do Tesouro Nacional. Utilizando regressões logísticas com bancos de dados empilhados, o trabalho encontrou dois resultados principais. Primeiro, as recessões, ou mesmo as desacelerações econômicas, são mais sofridas pelos grupos de menor escolaridade. Segundo, a política fiscal afeta mais intensamente a pobreza: por um lado, o superávit primário está associado a menores níveis de bem-estar da população; por outro lado, o gasto social da União pode ser utilizado para amenizar a pobreza durante as fases críticas dos ciclos.
\end{abstract}

Palavras-chave: Ciclos macroeconômicos; Economia do bem-estar; Modelos de cortes transversais agrupados; Economia brasileira, Pobreza.

\section{Abstract \\ Economic cycles and poverty composition in Brazil: an analysis of recent decades}

This aim of this study is to analyze the impact of macroeconomic cycles on poverty and its composition in Brazil from 1987 to 2005. Specifically, it intends to find answers to three questions: first, which demographic groups are most harmed in the recessive cycles; second, is economic growth enough to benefit all groups most associated with poverty; third, which macroeconomic policies are most associated with poverty and its alleviation. The study uses the PNAD household survey together with macroeconomic data from sources such as IPEA-DATA, The Central Bank of Brazil and The National Treasury Secretary. Using logistical regressions with pooled micro-data banks, the study found two principle results. First, economic decelerations are more harmful to people with less schooling. Second, fiscal policy significantly affects poverty: the primary surplus is associated with lower levels of well-

* Trabalho recebido em 17 de junho de 2011 e aprovado em 28 de abril de 2013.

** Economista do BNDES (Banco Nacional de Desenvolvimento Econômico e Social). E-mail: ricardoamartini@gmail.com.

${ }^{* * * *}$ Professora do Cedeplar (Centro de Desenvolvimento e Planejamento Regional) e do Departamento de Economia da UFMG (Universidade Federal de Minas Gerais) / Pesquisadora do CNPq (Conselho Nacional de Desenvolvimento Científico e Tecnológico), Belo Horizonte, MG, Brasil. E-mail: ahermeto@cedeplar.ufmg.br.

***** Professor do Cedeplar e do Departamento de Economia da UFMG / Pesquisador do CNPq, Belo Horizonte, MG, Brasil. E-mail: gonzaga@cedeplar.ufmg.br. 
being of the population. On the other hand, however, the federal social expenditure can be used to alleviate poverty during the critical stages of the cycles.

Keywords: Macroeconomic cycles; Welfare economics; Pooled cross-section models; Brazilian economy; Poverty.

JEL C29, E32, I31.

\section{Introdução}

O presente artigo aborda o impacto dos ciclos econômicos sobre os grupos demográficos brasileiros nas últimas décadas. O trabalho parte de estudos anteriores que mostram que os indicadores de desigualdade e de pobreza são afetados diretamente pelo desempenho macroeconômico de maneira diferenciada entre os diversos grupos de agentes e os setores da economia. Isto é, existem fatores associados às próprias características dos trabalhadores e de suas famílias que prejudicam determinados grupos de ingressar, de se manter e de progredir no mercado de trabalho. Esses fatores podem ser de ordem demográfica (como a composição das famílias e a existência de mecanismos de discriminação por raça e sexo), política (como o acesso a políticas de ingresso ao mercado de trabalho e de distribuição de renda), macroeconômica (como a distribuição de renda) e microeconômica (como o nível de qualificação e de experiência de cada trabalhador), os quais podem tornar a pobreza menos elástica ao crescimento econômico para determinadas pessoas do que para outras.

Dentre os estudos referidos ${ }^{1}$, destacam-se os trabalhos de Blank e Blinder (1986); Cutler e Katz (1991); Blank e Card (1993); Haveman e Schwabish (1999); Freeman (2001); Hines et al. (2001) e Hoynes et al. (2005) para os Estados Unidos; Brady (2004) para uma amostra de países desenvolvidos; Bourguignon e Goh (2004) para a Coréia do Sul; Maloney et al. (2004) e Antman e Mckenzie (2005) para o México; e de Aassve e Arpino (2007) para o Vietnã. Para o caso brasileiro, os trabalhos mais recentes sobre o tema são os de Neri e Thomas (2000) e de Justesen (2008). Os trabalhos, por serem realizados em bases de dados completamente distintas e por apresentarem diferentes estratégias empíricas, são pouco comparáveis entre si. De um modo geral, os estudos voltados às economias desenvolvidas tendem a concluir que, embora os movimentos de expansão beneficiem a maioria dos trabalhadores, os choques recessivos são mais intensos para trabalhadores de menores indicadores de produtividade (isto é, baixa qualificação e experiência no trabalho), e esse processo se reforçou desde a década de oitenta. Por outro lado, os estudos voltados às economias subdesenvolvidas tendem a encontrar fenômenos de exclusão social, tais como discriminação de raça, de gênero e de acesso a determinados bens de infraestrutura social, que explicam a heterogeneidade dos impactos dos choques. Um quadro-resumo das estratégias empíricas dos estudos citados, assim como suas variáveis explicadas e explicativas, encontra-se em anexo ao presente trabalho.

(1) A referência teórica mais forte citada nos primeiros estudos dessa linha de pesquisa é Okun (1965 e 1973). Os trabalhos posteriores focaram aspectos mais empíricos. 
Por isso, de acordo com Gafar (1998) e Deaton (2004), o crescimento econômico é necessário, mas não suficiente, para reduzir a pobreza de uma população. Para que a pobreza ceda, é necessário que o crescimento seja forte o suficiente para elevar a demanda agregada por empregos e elevar os salários reais de todos os trabalhadores. Isso não ocorre, por exemplo, se o crescimento for mais intensivo em capital físico, financeiro e humano do que em mão-de-obra, e concentrador de empregos sobre os indivíduos mais qualificados. Uma breve discussão sobre a possibilidade de viés do crescimento econômico em relação aos fatores de produção é realizada na segunda parte do trabalho.

Tendo em vista o discutido acima, os ciclos macroeconômicos podem ter impactos diferenciados sobre os grupos populacionais. Contudo, para o Brasil, as abordagens empíricas até agora realizadas tendem a focar apenas no impacto desses ciclos sobre os indivíduos identificados como pobres e não pobres, isto é, falta uma abordagem que leve em conta a composição da pobreza, ou seja, como os choques afetam diferenciadamente os grupos demográficos associados à pobreza. Por isso, o objetivo do presente trabalho é estimar e analisar para o caso brasileiro a partir do final da década de 1980 respostas para três questões básicas. Primeiro, se os grupos que sofrem mais durante os períodos de recessão ou de desaceleração do crescimento são aqueles associados a maior probabilidade de serem pobres, tais como as mulheres, os membros de famílias chefiadas por mulheres, os negros, os jovens e os menos escolarizados. Segundo, se o crescimento econômico é suficiente para garantir que os grupos demográficos convirjam em termos de renda familiar e bem-estar social. Terceiro, quais políticas macroeconômicas estão mais associadas à pobreza e a sua amenização.

O método aqui utilizado parte de uma interação entre microdados trianuais da Pesquisa Nacional por Amostra Domiciliar (PNAD), do IBGE, entre 1987 e 2005 e dados macroeconômicos do IPEA-DATA, Banco Central do Brasil e Secretaria do Tesouro Nacional. Os modelos foram estimados em nível individual pelo uso de uma regressão logística, para a probabilidade de ser pobre a partir da construção de linhas de pobreza estaduais deflacionadas por um índice de preços.

\section{Macroeconomia, mercado de trabalho e dispersão salarial: referências teóricas}

A visão por muito tempo dominante nas teorias sobre o crescimento econômico é que a sua dinâmica exerce um efeito de trickle-down sobre a pobreza, isto é, de transferência relativa de recursos dos mais ricos para os mais pobres. Segundo essa visão, a acumulação de capital tende a elevar o montante de recursos disponíveis nos mercados de crédito, de modo que os mais pobres têm cada vez mais condições de investir em seus negócios para procurar melhorar as suas condições de vida. Além disso, supondo-se que os indivíduos mais pobres tenham a maior 
parte dos seus rendimentos vindos do fator trabalho, espera-se que o impacto do desempenho macroeconômico sobre o seu bem-estar dependa das condições do mercado de trabalho ao longo do tempo.

Nesse sentido, a teoria de Arthur Okun (1965 e 1973) foi a pioneira em estudar a relação entre crescimento econômico e bem-estar social, mensurado pelo emprego do fator trabalho. Okun identificou que o crescimento e o desemprego são variáveis negativamente correlacionadas, mas não na mesma proporção, já que, com o progressivo crescimento da produtividade da mão-de-obra na economia, cada vez são necessários menos trabalhadores para produzir um mesmo montante de produto. E ainda, essa relação não é universal, mas depende de fatores institucionais e tecnológicos específicos a cada caso. Para o autor, um mercado de trabalho aquecido é benéfico aos trabalhadores mais pobres não apenas por significar a criação de novos empregos, mas também por melhorar a qualidade dos empregos existentes. Segundo Okun (1973), essa melhora na qualidade dos empregos não ocorre devido efeitos de substituição de empregados dentro das empresas de acordo com critérios de produtividade individual, mas sim pela contratação de novos empregados por parte das empresas mais produtivas, que pagam salários mais elevados aos seus contratados por mecanismos de salário-eficiência.

Particularmente ao caso brasileiro, as características do mercado de trabalho que explicam o seu comportamento frente à dinâmica macroeconômica são explicadas por autores como Mattos (2005) e Dedecca (1998b, 2005). Segundo Dedecca (2005), a principal característica do mercado de trabalho brasileiro é a presença simultânea de trabalhadores incluídos e excluídos dos mecanismos institucionais de proteção e de regulação. Mattos (2005), assim como Dedecca, afirma que essa heterogeneidade estrutural da economia brasileira, caracterizada pelo elevado nível de segmentação do mercado de trabalho, decorre do processo histórico de formação do mercado nacional. Isto é, a exclusão social no mercado de trabalho brasileiro nasceu da incapacidade da economia nacional, sobretudo a partir do ciclo do café e da industrialização acelerada após 1930, em absorver a mão-de-obra liberada pela escravidão e concentrada nas regiões mais pobres do país. Isso levou à divisão do mercado de trabalho brasileiro em dois setores básicos. Em primeiro lugar, um mercado interno de trabalho, ocupado por trabalhadores de setores da economia tecnologicamente avançados e estruturalmente oligopolizados. Em segundo lugar, um mercado externo de trabalho, ocupado por trabalhadores de setores com baixa taxa de inovações técnicas, cujos empregos e salários estão mais sujeitos a flutuações cíclicas. Nesse mercado externo, os trabalhadores estão mais sujeitos à exclusão social, já que seus empregos tendem a ser eliminados conforme avança o progresso tecnológico. Ou seja, em relação a esses trabalhos, a determinação do sentido da tecnologia afeta de maneira desigual os trabalhadores de acordo com sua posição na ocupação e seu setor de atividade econômica. Isto é, a inovação tecnológica absorve 
melhor os trabalhadores formais e que atuam nos ramos mais oligopolizados da economia (por exemplo, a indústria), em detrimento dos informais e dos que atuam em setores mais competitivos (por exemplo, os serviços).

Além desses fatores, outros autores caracterizam a mudança tecnológica viesada para o trabalho qualificado. Isto é, nesses estudos, a qualificação da mãode-obra é uma variável importante não apenas para identificar quais trabalhadores são mais beneficiados pelo crescimento econômico, mas também para explicar a própria trajetória da difusão tecnológica. Esse fator é capaz de explicar algumas características importantes das economias em desenvolvimento, como a adoção de tecnologias menos eficientes mesmo na disponibilidade de tecnologias mais eficientes, e a dispersão salarial de acordo com a variabilidade de escolaridade e de experiência no mercado de trabalho.

Portanto, uma série de estudos teóricos ${ }^{2}$ trabalham com o conceito de mudança tecnológica direcionada. A idéia básica de todos esses estudos é que a mudança tecnológica não é neutra, isto é, ela beneficia alguns fatores de produção e os agentes que detêm esses fatores de produção em detrimento dos demais. O estudo do viés da mudança tecnológica ajuda a esclarecer tanto os seus efeitos distributivos na economia, como também a identificação dos incentivos à pesquisa tecnológica na mesma. O mais importante exemplo de mudança tecnológica viesada relatado nesses estudos é o viés em relação à qualificação, o qual tem importantes efeitos sobre o desenvolvimento do mercado de trabalho e da estrutura da distribuição de renda salarial, e foi o caso predominante no mundo pós-guerra.

A idéia básica desses modelos teóricos é que a lucratividade dos fatores de produção não incentiva apenas a produção da tecnologia na economia, mas também a sua direção. Isso acontece devido à interação de dois efeitos. Em primeiro lugar, o efeito preço, segundo o qual há maiores incentivos para desenvolver tecnologias quando os bens produzidos por essas tecnologias têm preços relativos mais elevados. Em segundo lugar, o efeito escala, segundo o qual é mais lucrativo desenvolver tecnologias que têm um maior mercado. Uma vez que a tecnologia é vista como um bem não-rival, geralmente o efeito-escala tem poder de dominar o efeitopreço. Esses efeitos explicam a variação da distribuição de renda entre fatores de produção ao longo do crescimento econômico pelas características de duas situações de equilíbrio. Primeiro, em um equilíbrio de viés fraco, o crescimento da oferta relativa de um fator sempre induz uma mudança tecnológica viesada para esse fator. Segundo, em um equilíbrio de viés forte, se a elasticidade de substituição entre os fatores de produção for suficientemente elevada, o crescimento da oferta relativa de um fator induz a uma mudança tecnológica viesada a esse fator intensa o sufuciente para tornar a curva de demanda de tecnologia da economia positivamente inclinada.

(2) Por exemplo, Acemoglu (1998, 2002, 2003a, 2003b, 2007, 2011); Acemoglu e Zilibotti (2001). 
Isso, por sua vez, ocorre porque o produto marginal desse fator que teve sua oferta expandida cresce em relação aos demais fatores ${ }^{3}$.

Acemoglu (2011) relaciona a teoria da mudança tecnológica viesada com o aumento da desigualdade salarial nos países ocidentais desenvolvidos nas últimas décadas. Segundo o autor, durante todo o século vinte houve uma crescente oferta de mão-de-obra qualificada nesses países de modo que, pelo equilíbrio de viés forte, induziu uma mudança tecnológica que elevou a produtividade marginal do trabalho qualificado, aumentando sua remuneração em relação à do trabalho não-qualificado. $\mathrm{O}$ viés do crescimento econômico para a qualificação se acelerou nos últimos 25 anos devido à combinação da histerese do crescimento acelerado da oferta de mão-deobra qualificada nos anos 1970 com um choque tecnológico exógeno que favoreceu esse fator de produção.

Krusell et al. (2000) apresenta outra explicação para os maiores retornos do trabalho qualificado a partir da década de 1970. Para o autor, a aceleração do viés de mudança tecnológica das últimas décadas foi decorrente de um aumento da produtividade marginal do capital, que elevou a demanda por equipamentos, que são um fator de produção complementar à mão-de-obra qualificada. Assim, o prêmio do mercado de trabalho à qualificação aumentou, e com ele, a desigualdade.

Aghion et al (2002) formulou um estudo sobre o papel da generalidade do progresso tecnológico sobre a desigualdade de salários. Segundo o seu trabalho, o conceito da generalidade tecnológica apresenta dois componentes. Em primeiro lugar, a idéia de transferibilidade, que é a capacidade da tecnologia permitir a transferência de habilidades entre diferentes setores da economia. Em outras palavras, corresponde à fração de conhecimentos acumulados que o trabalhador pode carregar consigo quando muda de setor de atividade. Em segundo lugar, a idéia de compatibilidade, que é a capacidade dos equipamentos de capital físico de tecnologia antiga serem adaptados à tecnologia nova. No modelo, pressupõe-se que investimentos na qualificação dos trabalhadores mais jovens elevam sua adaptabilidade às novas tecnologias. $\mathrm{O}$ estudo chega ao resultado de que, quanto mais generalista for a mudança tecnológica - isto é, mais transferível e mais compatível - maior será o prêmio para os trabalhadores mais adaptáveis, o que eleva a desigualdade de salários no longo prazo. Essa tendência pode ser contrabalanceada se for assumido que os trabalhadores já integrados ao mercado de trabalho também possam se qualificar, elevando sua adaptabilidade. Além disso, se a mudança tecnológica for mais intensiva em transferibilidade, eleva o prêmio pela experiência, devido à valorização do conhecimento acumulado, sendo viesada para os trabalhadores de mais idade.

(3) Mais uma vez, esse resultado está relacionado ao pressuposto que a tecnologia é produzida pela agregação de idéias, que são definidas como bens não-rivais. Por isso, a função de produção agregada da economia apresenta retornos crescentes de escala, de modo que o aumento da oferta de um fator eleva a sua produtividade marginal e, consequentemente, o seu preço relativo. 


\section{Metodologia}

\subsection{Modelo empírico}

Sucintamente, o objetivo deste artigo é explicar a probabilidade de ser pobre no Brasil em função de uma série de variáveis, tanto de ordem individual, como de ordem macroeconômica, seja de indicadores de ciclos, seja de indicadores de políticas. Essa estratégia empírica é semelhante à utilizada anteriormente por Freeman (2001) e Brady (2004), mas procura avançar em relação a esses trabalhos. Isto é, ao contrário de ambos, aqui se procura agregar variáveis micro e macroeconômicas em um mesmo modelo empírico. Freeman (2001) utilizou séries temporais e dados em painel para estimar um modelo semelhante ao proposto por Okun, e fez o cruzamento de seus resultados com variáveis microeconômicas em uma análise estatística descritiva. Brady (2004) utiliza variáveis micro e macroconômicas em seu modelo empírico, mas sua unidade de observação são países - isto é, usa dados agregados - e não indivíduos. Para o Brasil, os trabalhos mais semelhantes ao presente são os de Neri e Thomas (2000) e o de Justesen (2008). O primeiro procura calcular o risco de indivíduos entrarem e saírem da condição de pobreza em expansões e recessões econômicas em função de variáveis educacionais e indicadores do mercado de trabalho. Contudo, o estudo não estende a sua análise à composição interna da pobreza, e tampouco às características dos ciclos mensurados por variáveis macroeconômicas. Justesen (2008), por sua vez, observa o desempenho no mercado de trabalho dos grupos associados à pobreza no Brasil controlando pelos ciclos econômicos das últimas décadas. Contudo, faz isso por uma análise estatística descritiva, isto é, não produz um modelo empírico com todas as suas variáveis para identificar as mais importantes.

Neste artigo, foram estimados seis modelos empíricos. Um desses modelos inclui apenas variáveis independentes de natureza econômica, isto é, a pobreza sendo explicada pelo desemprego, pela inatividade, pelos anos de estudo (como uma proxy para o capital humano acumulado, que determina a produtividade) e pela idade do indivíduo (como uma proxy para a experiência no mercado de trabalho). Essas variáveis agregam os determinantes básicos do mercado de trabalho, e estão presentes nos modelos teóricos apresentados anteriormente e na maior parte dos estudos empíricos levantados no quadro comparativo em anexo.

O segundo modelo apresenta variáveis de controle socioeconômicas, demográficas e regionais, nesse caso, tomando o Distrito Federal como base. Dentre essas variáveis de controle, selecionadas em acordo com a bibliografia já existente, estão presentes o sexo do indivíduo ${ }^{4}$, a sua raça ${ }^{5}$, as características do domicílio ${ }^{6}$, a

(4) Cutler e Katz (1991); Freeman (2001); Antman e Mckenzie (2005); Aasve e Apino (2007); Justesen (2008).

(5) Freeman (2001); Aasve e Apino (2007).

(6) Cutler e Katz (1991), Blank e Card (1993), Freeman (2001), Brady (2004), Maloney et al (2004), Antman e Mckenzie (2005), Hoynes et al (2005), Aasve e Apino (2007) e Justesen (2008). 
região do Brasil em que reside ${ }^{7}$, a categoria de posição na ocupação ${ }^{8}$ e o grupo de ramos de atividade no mercado de trabalho ${ }^{9}$ em que atua.

O terceiro e o quinto modelos incluem como variáveis de interesse os indicadores de ciclo econômico, respectivamente para os períodos de recessão e de expansão. Essa estratégia é semelhante à utilizada nos trabalhos de Haveman e Schwabish (1999); Neri e Thoas (2000); Freeman(2001); Hines et al. (2001); Maloney et al. (2004) e Justesen (2008). Contudo, ao contrário dos anteriores, o presente trabalho procura identificar não só como os ciclos se relacionam com a pobreza, mas também como se relacionam com os grupos sociais associados à pobreza (aqui identificados como os menos escolarizados, os negros e os integrantes de famílias chefiadas por mulheres). Por isso, aqui os indicadores de ciclos econômicos são interagidos com as variáveis que identificam esses grupos sociais.

Por fim, o quarto e o sexto modelos incluem como variáveis de interesse os indicadores de política econômica, respectivamente com os indicadores de expansão e de recessão. Dentre esses indicadores de política, destaca-se que já são encontrados na bibliografia a inflação (Cutler e Katz, 1991) e os gastos sociais (Blank; Card, 1993; Brady, 2004; Hoynes et al., 2005). Contudo, o presente trabalho também procura identificar o papel da política fiscal e da política monetária sobre a pobreza. Destacase que, devido à presença de multicolinearidade, não é possível estimar um modelo englobando todas as variáveis de interesse (ciclos e políticas) ao mesmo tempo.

O método aqui adotado para os dados longitudinais agrupados busca estimar a probabilidade de um indivíduo estar abaixo da linha de pobreza ao longo dos ciclos econômicos. Assim, em um modelo de variáveis dependentes binárias, a variável dependente y assume um de dois valores possíveis, igual a um (ser pobre), ou igual a zero (não ser pobre). O objetivo de se trabalhar com esse tipo de modelo empírico é estimar, ou prever, a probabilidade de sucesso e de insucesso, condicional a um dado vetor $\mathrm{x}$ de variáveis explicativas. No presente estudo, utiliza-se um modelo logístico em que se apresenta o logito ${ }^{10}$ da probabilidade de ser pobre, isto é, de estar abaixo da linha de pobreza considerada, como função de um vetor de variáveis explicativas.

Após os procedimentos matemáticos de linearização do modelo logístico, os modelos estimados são, respectivamente, os seguintes:

(7) Para o caso norte-americano, os controles regionais estão presentes em Blank e Card (1993) e Hoynes et al. (2005).

(8) Neri e Thomas (2000); Maloney et al. (2004).

(9) Cutler e Katz (1991); Freeman (2001); Brady (2004) e Bourguignon e Goh (2004).

(10) O logito (ou logit) é a probabilidade do odd ratio, isto é, a razão da probabilidade de ser pobre com a probabilidade de não ser pobre. 


$$
\begin{aligned}
& \mathrm{y}_{\mathrm{it}}=\beta_{0}+\beta_{1} \mathrm{X}_{\mathrm{it}}+\mathrm{e}_{\mathrm{it}} \\
& \mathrm{y}_{\mathrm{it}}=\beta_{0}+\beta_{1} \mathrm{X}_{\mathrm{it}}+\beta_{2} \mathrm{D}_{\mathrm{it}}+\mathrm{e}_{\mathrm{it}} \\
& \mathrm{y}_{\text {it }}=\beta_{0}+\beta_{1} \mathrm{X}_{\mathrm{it}}+\beta_{2} \mathrm{D}_{\mathrm{it}}+\beta_{3} \mathrm{Z}_{1 \mathrm{it}}+\mathrm{e}_{\mathrm{it}} \\
& \mathrm{y}_{\mathrm{it}}=\beta_{0}+\beta_{1} \mathrm{X}_{\mathrm{it}}+\beta_{2} \mathrm{D}_{\mathrm{it}}+\beta_{3} \mathrm{Z}_{1 \mathrm{it}}+\mathrm{P}_{\mathrm{it}}+\mathrm{e}_{\mathrm{it}} \\
& \mathrm{y}_{\mathrm{it}}=\beta_{0}+\beta_{1} \mathrm{X}_{\mathrm{it}}+\beta_{2} \mathrm{D}_{\mathrm{it}}+\beta_{3} \mathrm{Z}_{2 \mathrm{it}}+\mathrm{e}_{\mathrm{it}} \\
& \mathrm{y}_{\mathrm{it}}=\beta_{0}+\beta_{1} \mathrm{X}_{\mathrm{it}}+\beta_{2} \mathrm{D}_{\mathrm{it}}+\beta_{3} \mathrm{Z}_{2 \mathrm{it}}+\mathrm{P}_{\mathrm{it}}+\mathrm{e}_{\mathrm{it}}
\end{aligned}
$$

Nesses modelos, $\mathrm{y}_{\text {it }}$ é o vetor de dados sobre a posição dos indivíduos frente à linha de pobreza de seu estado e sobre sua renda familiar, $\mathrm{X}_{\mathrm{it}}$ é o vetor de variáveis de controle econômicas, $\mathrm{D}_{\mathrm{it}}$ é o vetor das demais variáveis de controle socioeconômicas e demográficas, $Z_{1 i t}$ é o vetor de variáveis de interesse de ciclos econômicos para os períodos de expansão, $Z_{2 i t}$ é o vetor de variáveis de interesse de ciclos econômicos para os períodos de recessão, e $\mathrm{P}_{\text {it }}$ é o vetor de variáveis de interesse de política econômica.

Como o trabalho utiliza sete bancos de microdados conjuntamente, o procedimento de estimação utilizado é o Pooled OLS, também conhecido como método de Mínimos Quadrados Ordinários Empilhados ${ }^{11}$. Esse modelo ignora quaisquer correlações entre os regressores e quaisquer perturbações aleatórias que variam de acordo com os indivíduos e o tempo. O modelo assume também que $\beta=$ $\beta \mathrm{j} \forall \mathrm{j}$, t. Esse modelo especifica que os coeficientes da equação são constantes para todos os indivíduos, o que é uma hipótese básica de estimação por cross-section:

$$
\mathrm{Y}_{\mathrm{it}}=\alpha+\mathrm{X}_{\mathrm{it}}{ }^{\prime} \beta+\mathrm{u}_{\mathrm{it}} \quad \mathrm{i}=1, \ldots, \mathrm{N} \quad \mathrm{t}=1, \ldots, \mathrm{T}
$$

A estimação desse modelo se faz via a regressão por mínimos quadrados da equação (7), considerando cada observação ( $\mathrm{N}$ x $\mathrm{T}$ ) como sendo um indivíduo diferente. A consistência das estimativas depende de $\operatorname{Cov}\left(\mathrm{u}_{\mathrm{it}}, \mathrm{x}_{\mathrm{it}}\right)=0$ e $\operatorname{Cov}\left(\alpha, \mathrm{x}_{\mathrm{it}}\right)=$ 0 .

É importante destacar que, como o objetivo do presente trabalho é estimar o impacto dos ciclos econômicos sobre o bem-estar de grupos sociais brasileiros, a princípio, a metodologia de pseudo-painel poderia parecer mais adequada. O pseudopainel baseia-se na observação de variáveis observadas por coortes transversais repetidas, e não por indivíduos, como nos painéis tradicionais. Assim, são os grupos ou coortes de observações que são seguidos ao longo do tempo, e não as unidades de cross-section, o que também pode ser considerado um método de se controlar os efeitos individuais. As coortes, por sua vez, podem ser divididas em sub-coortes, controlando-se por subgrupos de indivíduos com variáveis de interesse. As técnicas de pseudo-painel apresentam uma série de vantagens. Em primeiro lugar, o método não sofre atrito. Em segundo lugar, as coortes podem ser construídas para qualquer

(11) Maiores detalhes sobre os métodos econométricos aqui apresentados podem ser encontrados em Wooldridge (2006) e Cameron e Trivedi (2005). 
característica de interesse, de modo que essa técnica se torna muito flexível. Por fim, o pseudo-painel permite a cominação de bases de distintas para a construção de coortes.

Basicamente, uma coorte é um grupo de indivíduos com as mesmas características de interesse, definidas para todos os períodos. Cada indivíduo só pode fazer parte de uma coorte, uma vez que são agrupados de acordo com o valor médio de suas características. As coortes são seguidas ao longo do tempo, do mesmo modo que as unidades de cross-section presentes nos modelos de painel. Uma hipótese fundamental para a consistência dos estimadores é que esse termo seja estacionário, isto é, fixo ao longo do tempo. Contudo, no presente estudo, essa hipótese não é aplicável, uma vez que pelo menos dois dos grupos considerados - famílias chefiadas por mulheres e proporção de indivíduos com escolaridade superior a dez anos de estudo - apresentaram considerável variação ao longo do período de análise ${ }^{12}$.

\subsection{Base de dados}

A fonte de microdados utilizada no presente trabalho é a Pesquisa Nacional por Amostra de Domicílios (PNAD), realizada pelo Instituto Brasileiro de Geografia e Estatística (IBGE), para o período de 1987 a 2005 . Essa fonte de microdados consiste em um sistema de pesquisas domiciliares implantado a partir de 1967, com o objetivo de se produzir informações para o estudo do desenvolvimento socioeconômico e demográfico do Brasil. Por ter uma periodicidade anual, apresenta informações novas e complementares àquelas presentes no Censo Demográfico, de periodicidade decenal. As informações presentes na PNAD englobam diversas características socioeconômicas da população brasileira. Em termos de periodicidade permanente, essas características incluem as características gerais da população, assim como indicadores de educação, trabalho, rendimentos e habitação. Além desses, a pesquisa inclui de maneira variável alguns outros indicadores, voltados a questões como a migração e as condições de saúde e de nutrição da população.

É importante destacar que a PNAD passou por mudanças metodológicas na definição de indicadores de mercado de trabalho no início dos anos 90. Por exemplo, a partir desse período os trabalhadores não remunerados ou dedicados ao autoconsumo ou a autoprodução passaram a ser considerados ativos (Dedecca, 1998a). Além disso, o questionário sobre o emprego e desemprego tornou-se muito mais elaborado e complexo. Passou a ser considerado desempregado o individíduo que, na semana de referência da pesquisa, esteve sem trabalho, tendo disponibilidade para o trabalho e tendo procurado trabalho. Essa nova metodologia teve o objetivo

(12) Exemplos de estudos com objetivos semelhantes a este em que o método de pseudo-painel foi utilizado de maneira bem-sucedida são Hines et al. (2001); Bourguignon e Goh (2004) e Antman e Mckenzie (2005). 
de incorporar ao contigente de desempregados os trabalhadores desencorajados de procurar emprego, ou aqueles empregados em atividades precárias e descontínuas. Além disso, permitiu a decomposição do desemprego de acordo com suas causas, tornando passível de identificar o desemprego estrutural e o desemprego cíclico.

O presente trabalho analisou dados de sete bancos da PNAD empilhados, para os anos de 1987, 1990, 1993, 1996, 1999, 2002 e 2005. A amostra total, em nível individual, compreende 985.669 observações de pessoas entre 25 e 60 anos de idade, distribuídas da seguinte maneira entre os anos:

Tabela 1

Distribuição amostral por ano

\begin{tabular}{cccc}
\hline Ano & Freqüência & Proporção (\%) & Cumulativo (\%) \\
\hline 1987 & 109.323 & 11,09 & 11,09 \\
1990 & 116.605 & 11,83 & 22,92 \\
1993 & 128.340 & 13,02 & 35,94 \\
1996 & 136.177 & 13,82 & 49,76 \\
1999 & 148.207 & 15,04 & 64,79 \\
2002 & 165.753 & 16,82 & 81,61 \\
2005 & 181.264 & 18,39 & 100 \\
Total & 985.669 & 100 &
\end{tabular}

Fonte: Elaboração própria a partir de dados da PNAD.

Os macrodados incluídos no trabalho, referentes à evolução da conjuntura macroeconômica e das políticas fiscal e monetária no Brasil, provêm de fontes como a Secretaria do Tesouro Nacional (STN), o Banco Central do Brasil (BACEN), o Instituto Brasileiro de Geografia e Estatística (IBGE) e o Instituto de Pesquisa Econômica Aplicada (IPEA).

\subsection{Análise descritiva das variáveis}

As variáveis incluídas no trabalho estão descritas nos quadros a seguir.

Quadro 1

Variável Dependente $\left(\mathrm{Y}_{\mathrm{it}}\right)$

\begin{tabular}{|c|l|l|}
\hline Variável & \multicolumn{1}{|c|}{ Nome } & \multicolumn{1}{c|}{ Descrição } \\
\hline Pobre & $\begin{array}{l}\text { Condição frente à Linha de } \\
\text { Pobreza Estadual }\end{array}$ & $\begin{array}{l}\text { Dummy com valor igual a 1 se o indivíduo } \\
\text { estiver abaixo da linha de pobreza de seu } \\
\text { estado, e 0 caso contrário. }\end{array}$ \\
\hline
\end{tabular}

Fonte: Elaboração própria a partir das variáveis da PNAD. 
A construção das linhas de pobreza estaduais foi realizada de acordo com a metodologia desenvolvida por Rocha (1997). Assim, buscou-se mensurar o valor monetário real de uma cesta de produtos alimentares capaz de suprir o mínimo de calorias diárias recomendadas para os indivíduos, sem considerar características individuais como idade, sexo e raça. De acordo com estudos da Organização das Nações Unidas para Agricultura e Alimentação (FAO), citados no estudo de Rocha, esse mínimo equivale a cerca de 2.100 calorias.

De acordo com Rocha (1997), as evidências empíricas apontam que as estruturas de consumo e de preços dos alimentos são bastante diferenciadas ao longo do país. Particularmente no caso dos preços, esses são afetados por um conjunto de determinantes de natureza eminentemente local, tais como a localização das atividades produtivas agropecuárias e agroindustriais, a acessibilidade ao mercado consumidor, e a existência e a qualidade das redes de comercialização. Por este motivo, as cestas de consumo alimentar definidas no presente trabalho para a construção das linhas de pobreza são fixas ao longo do tempo em sua composição, mas são diferenciadas para os estados brasileiros, de acordo com os padrões alimentares dos domicílios de baixa renda - isto é, os 20\% mais pobres da distribuição de renda - de cada localidade, de acordo com observações realizadas com base na Pesquisa de Orçamento Familiar (POF) de $1996^{13}$. Com base nessas observações, foi construída uma linha de pobreza por unidade da federação de acordo com a renda dos indivíduos ${ }^{14}$. O deflacionamento dos valores das linhas de pobreza estaduais foi realizado de acordo com o Índice Nacional de Preços ao Consumidor (INPC), tendo como referência o ano de 2006, seguindo a metodologia sugerida por Corseul e Foguel (2002). Como não foi possível formular indicadores de preços específicos para o deflacionamento nas regiões rural, urbana e metropolitana de cada estado, optou-se pela construção de uma única linha de pobreza por unidade da federação.

(13) Destaca-se que a metodologia de construção das linhas de pobreza baseadas no gasto calórico das famílias, tal como proposto por Rocha (1997) tem duas limitações principais, tal como descrito por Soares (2009). Em primeiro lugar, o processo de construção das cestas de consumo alimentares via dados da POF é repleto de decisões arbitrárias. Em segundo lugar, o método não verifica o impacto da redução dos preços absolutos dos bens não-alimentares sobre o bem-estar das famílias, cujo efeito, de acordo com a teoria econômica, deveria ser positivo. Contudo, apesar dessas limitações, considera-se que essa metodologia é a mais apropriada para o presente trabalho, pois os seus resultados estimados são melhor comparáveis com os de estudos anteriores.

(14) As linhas de pobreza são de elaboração própria, tendo como referência a linha de pobreza apresentada pelo Instituto de Estudos do Trabalho e Sociedade (IETS), desenvolvida por Sônia Rocha e disponível no site www. iets.gov.br. 
Quadro 2

Variáveis de interesse - Indicadores de Ciclo econômico $\left(Z_{1 \text { it }}\right.$ e $\left.Z_{2 i t}\right)$

\begin{tabular}{|c|c|c|}
\hline Variável & Nome & Descrição \\
\hline $\begin{array}{l}\text { Interação entre expansão e } \\
\text { chefia feminina; interação entre } \\
\text { recessão e chefia feminina }\end{array}$ & $\begin{array}{l}\text { Domicílios Chefiados por } \\
\text { Mulheres nos Anos de } \\
\text { Expansão e Recessão }\end{array}$ & $\begin{array}{l}\text { Interação entre os anos de } \\
\text { expansão e de recessão e a } \\
\text { chefia do domicílio por mulher. }\end{array}$ \\
\hline $\begin{array}{l}\text { Interação entre expansão e raça } \\
\text { negra; interação entre recessão } \\
\text { e raça negra }\end{array}$ & $\begin{array}{l}\text { Raça nos Anos de Expansão e } \\
\text { Recessão }\end{array}$ & $\begin{array}{l}\text { Interação entre os anos de } \\
\text { expansão e recessão e a raça } \\
\text { dos indivíduos. }\end{array}$ \\
\hline $\begin{array}{l}\text { Interação entre expansão e } \\
\text { escolaridade } 0 \text { a } 3 \text {; interação } \\
\text { entre recessão e escolaridade } \\
0 \text { a } 3\end{array}$ & $\begin{array}{l}\text { Indivíduos com } 0 \text { a } 3 \text { Anos de } \\
\text { Estudo nos Anos de Expansão } \\
\text { e Recessão }\end{array}$ & $\begin{array}{l}\text { Interação entre os anos de } \\
\text { expansão e de recessão e os } \\
\text { indivíduos com } 0 \text { a } 3 \text { anos de } \\
\text { estudo. }\end{array}$ \\
\hline $\begin{array}{l}\text { Interação entre expansão e } \\
\text { escolaridade } 4 \text { a } 7 \text {; interação } \\
\text { entre recessão e escolaridade } \\
4 \text { a } 7\end{array}$ & $\begin{array}{l}\text { Indivíduos com } 4 \text { a } 7 \text { Anos de } \\
\text { Estudo nos Anos de Expansão } \\
\text { e Recessão }\end{array}$ & $\begin{array}{l}\text { Interação entre os anos de } \\
\text { expansão e de recessão e os } \\
\text { indivíduos com } 4 \text { a } 7 \text { anos de } \\
\text { estudo. }\end{array}$ \\
\hline $\begin{array}{l}\text { Interação entre expansão e } \\
\text { escolaridade } 8 \text { a } 10 \text {; interação } \\
\text { entre recessão e escolaridade } \\
8 \text { a } 10\end{array}$ & $\begin{array}{l}\text { Indivíduos com } 8 \text { a } 10 \text { Anos de } \\
\text { Estudo nos Anos de Expansão } \\
\text { e Recessão }\end{array}$ & $\begin{array}{l}\text { Interação entre os anos de } \\
\text { expansão e de ecessão e os } \\
\text { indivíduos com } 8 \text { a } 10 \text { anos de } \\
\text { estudo. }\end{array}$ \\
\hline $\begin{array}{l}\text { Interação entre expansão e } \\
\text { escolaridade } 11 \text { a } 15 \text {; interação } \\
\text { entre recessão e escolaridade } \\
11 \text { a } 15\end{array}$ & $\begin{array}{l}\text { Indivíduos com } 11 \text { a } 15 \\
\text { Anos de Estudo nos Anos de } \\
\text { Expansão e Recessão }\end{array}$ & $\begin{array}{l}\text { Interação entre os anos de } \\
\text { expansão e de recessão e os } \\
\text { indivíduos com } 11 \text { a } 15 \text { anos de } \\
\text { estudo. }\end{array}$ \\
\hline $\begin{array}{l}\text { Ano no ciclo de expansão; ano } \\
\text { no ciclo de recessão }\end{array}$ & $\begin{array}{l}\text { Posição do Ano no Ciclo de } \\
\text { Expansão e Recessão }\end{array}$ & $\begin{array}{l}\text { Valor da posição de cada ano } \\
\text { no seu ciclo de expansão e } \\
\text { de recessão, de acordo com o } \\
\text { Quadro } 1 .\end{array}$ \\
\hline
\end{tabular}

Fonte: Elaboração própria a partir das variáveis da PNAD. No caso dos grupos educacionais, o conjunto tomado como base é o de indivíduos com 16 ou mais anos de estudo.

Quadro 3

Variáveis de Interesse - Indicadores de Política Macroeconômica $\left(\mathrm{P}_{\mathrm{it}}\right)$

\begin{tabular}{|l|l|l|}
\hline \multicolumn{1}{|c|}{ Variável } & \multicolumn{1}{|c|}{ Nome } & \multicolumn{1}{c|}{ Descrição } \\
\hline IPCA & $\begin{array}{l}\text { Indice de Preços } \\
\text { ao Consumidor } \\
\text { Acumulado }\end{array}$ & Inflação acumulada ao ano. Fonte: IPEA-DATA. \\
\hline Selic real & Taxa Selic Real & $\begin{array}{l}\text { Taxa média de juros Selic ao ano, descontada a } \\
\text { inflação. Fonte: BCB-DEMAB. }\end{array}$ \\
\hline
\end{tabular}

Continua... 
Quadro 3 - Continuação

\begin{tabular}{|l|l|l|}
\hline \multicolumn{1}{|c|}{ Variável } & Nome & Descrição \\
\hline Gasto social & Gasto Público Social & $\begin{array}{l}\text { Gastos da União com educação, cultura, saúde, } \\
\text { saneamento, assistência e previdência como } \\
\text { proporção do PIB. Fonte: Secretaria do Tesouro } \\
\text { Nacional. }\end{array}$ \\
\hline $\begin{array}{l}\text { Gasto primário } \\
\text { Superávit } \\
\text { primario }\end{array}$ & Gasto Público Primário & $\begin{array}{l}\text { Gastos totais da União, descontados os } \\
\text { pagamentos de juros da dívida, como proporção } \\
\text { do PIB. Fonte: Secretaria do Tesouro Nacional. }\end{array}$ \\
\hline
\end{tabular}

Fonte: Elaboração própria a partir de dados do Banco Central do Brasil, do IPEA-DATA e da Secretaria do Tesouro Nacional.

Quadro 4

Variáveis de controle do Modelo Básico de Capital Humano $\left(\mathrm{X}_{\mathrm{it}}\right)$

\begin{tabular}{|l|l|l|}
\hline \multicolumn{1}{|c|}{ Variável } & \multicolumn{1}{|c|}{ Nome } & \multicolumn{1}{c|}{ Descrição } \\
\hline Desempregado & Desemprego & $\begin{array}{l}\text { Dummy com valor igual a 1 se o } \\
\text { indivíduo não está empregado, mas está } \\
\text { procurando emprego, e 0 caso contrário. }\end{array}$ \\
\hline Inativo & Inatividade & $\begin{array}{l}\text { Dummy com valor igual a 1 se o } \\
\text { indivíduo não está empregado e não está } \\
\text { procurando emprego, e caso contrário. }\end{array}$ \\
\hline Anos de estudo & Anos de Estudo & Número de anos de estudo do indivíduo. \\
\hline Idade & Idade & Idade do indivíduo. \\
\hline Idade2 & Idade ao Quadrado & Quadrado da idade do indivíduo. \\
\hline
\end{tabular}

Fonte: Elaboração própria a partir das variáveis da PNAD.

Quadro 5

Variáveis de controle sócio-econômicas e demográficas $\left(\mathrm{D}_{\mathrm{it}}\right)$

\begin{tabular}{|l|l|l|}
\hline Variável & Nome & \multicolumn{1}{|c|}{ Descrição } \\
\hline Mulher & Sexo & $\begin{array}{l}\text { Dummy com valor igual a 1 se o indivíduo for mulher, e } \\
\text { igual a 0 se for homem. }\end{array}$ \\
\hline Negro & Negro & $\begin{array}{l}\text { Dummy com valor igual a 1 se o indivíduo é negro, índio } \\
\text { ou pardo, e 0 caso contrário. }\end{array}$ \\
\hline Urbano & Urbano & $\begin{array}{l}\text { Dummy com valor igual a 1 se o domicílio encontra-se em } \\
\text { uma região urbana,e 0 caso contrário. }\end{array}$ \\
\hline $\begin{array}{l}\text { Tamanho da } \\
\text { família }\end{array}$ & $\begin{array}{l}\text { Tamanho da } \\
\text { Família }\end{array}$ & $\begin{array}{l}\text { Número de membros da família do indivíduo, contando } \\
\text { agregados. }\end{array}$ \\
\hline
\end{tabular}

Continua... 
Quadro 5 - Continuação

\begin{tabular}{|c|c|c|}
\hline Variável & Nome & Descrição \\
\hline Chefe mulher & $\begin{array}{l}\text { Mulher Chefe } \\
\text { de Família }\end{array}$ & $\begin{array}{l}\text { Dummy com valor igual a } 1 \text { se o indivíduo pertence à } \\
\text { família chefiada por mulher, e } 0 \text { caso contrário. }\end{array}$ \\
\hline Norte & Região Norte & $\begin{array}{l}\text { Dummy com valor igual a } 1 \text { se o indivíduo reside na } \\
\text { Região Norte do país, e } 0 \text { caso contrário. }\end{array}$ \\
\hline Nordeste & $\begin{array}{l}\text { Região } \\
\text { Nordeste }\end{array}$ & $\begin{array}{l}\text { Dummy com valor igual a } 1 \text { se o indivíduo reside na } \\
\text { Região Nordeste do país, e } 0 \text { caso contrário. }\end{array}$ \\
\hline Sudeste & Região Sudeste & $\begin{array}{l}\text { Dummy com valor igual a } 1 \text { se o indivíduo reside na } \\
\text { Região Sudeste do país, e } 0 \text { caso contrário. }\end{array}$ \\
\hline Sul & Região Sul & $\begin{array}{l}\text { Dummy com valor igual a } 1 \text { se o indivíduo reside na } \\
\text { Região Sul do país, e } 0 \text { caso contrário. }\end{array}$ \\
\hline Centro-oeste & $\begin{array}{l}\text { Região Centro- } \\
\text { Oeste }\end{array}$ & $\begin{array}{l}\text { Dummy com valor igual a } 1 \text { se o indivíduo reside na Região } \\
\text { Centro-Oeste do país, excluindo-se o Distrito Federal, e } 0 \\
\text { caso contrário. }\end{array}$ \\
\hline Informal & $\begin{array}{l}\text { Trabalhador } \\
\text { Informal }\end{array}$ & $\begin{array}{l}\text { Dummy com valor igual a } 1 \text { se o trabalhador é informal, e } \\
0 \text { caso contrário. }\end{array}$ \\
\hline Integral & $\begin{array}{l}\text { Trabalhador } \\
\text { Integral }\end{array}$ & $\begin{array}{l}\text { Dummy com valor igual a } 1 \text { se o indivíduo trabalha mais } \\
\text { de } 30 \text { horas semanais, e } 0 \text { caso contrário. }\end{array}$ \\
\hline Técnico & $\begin{array}{l}\text { Trabalhador } \\
\text { Técnico }\end{array}$ & $\begin{array}{l}\text { Dummy com valor igual a } 1 \text { se o trabalhador exerce } \\
\text { atividade técnica, científica, artística ou assemelhada, e } 0 \\
\text { caso contrário. }\end{array}$ \\
\hline Administrador & $\begin{array}{l}\text { Trabalhador } \\
\text { Administrativo }\end{array}$ & $\begin{array}{l}\text { Dummy com valor igual a } 1 \text { se o trabalhador exerce } \\
\text { atividade administrativa, incluindo serviço público, e } 0 \\
\text { caso contrário. }\end{array}$ \\
\hline Agropecuária & $\begin{array}{l}\text { Trabalhador } \\
\text { Agropecuário }\end{array}$ & $\begin{array}{l}\text { Dummy com valor igual a } 1 \text { se o trabalhador exerce } \\
\text { atividade agropecuária ou de produção extrativa vegetal e } \\
\text { animal, e } 0 \text { caso contrário. }\end{array}$ \\
\hline Indústria & $\begin{array}{l}\text { Trabalhador da } \\
\text { Indústria }\end{array}$ & $\begin{array}{l}\text { Dummy com valor igual a } 1 \text { se o trabalhador exerce } \\
\text { atividade na indústria de transformação, e } 0 \text { caso contrário. }\end{array}$ \\
\hline Comércio & $\begin{array}{l}\text { Trabalhador do } \\
\text { Comércio }\end{array}$ & $\begin{array}{l}\text { Dummy com valor igual a } 1 \text { se o trabalhador exerce } \\
\text { atividade no comércio ou ocupações auxiliares, e } 0 \text { caso } \\
\text { contrário. }\end{array}$ \\
\hline Transportes & $\begin{array}{l}\text { Trabalhador de } \\
\text { Transportes }\end{array}$ & $\begin{array}{l}\text { Dummy com valor igual a } 1 \text { se o trabalhador exerce } \\
\text { atividade nos setores de transporte e comunicação, e } 0 \text { caso } \\
\text { contrário. }\end{array}$ \\
\hline Serviços & $\begin{array}{l}\text { Trabalhador de } \\
\text { Serviços }\end{array}$ & $\begin{array}{l}\text { Dummy com valor igual a } 1 \text { se o trabalhador exerce } \\
\text { atividade de prestação de serviços, e } 0 \text { caso contrário. }\end{array}$ \\
\hline Empregador & Empregador & $\begin{array}{l}\text { Dummy com valor igual a } 1 \text { se o indivíduo é empregador, } \\
\text { e } 0 \text { caso contrário. }\end{array}$ \\
\hline
\end{tabular}

Fonte: Elaboração própria a partir das variáveis da PNAD. Em relação as dummies de grupo de ocupação, o conjunto tomado como base é o de "outros setores". 
Além dessas variáveis, foram incluídas no modelo uma série de dezoito coortes que agrupam os indivíduos de acordo com o ano de seu nascimento. Cada coorte é uma variável dummy que se refere a um período trienal, de modo que a Coorte 1 tem valor igual a um para os indivíduos nascidos entre 1927 e 1929, e zero caso contrário, e assim segue até a Coorte 18, que tem valor igual a um para os indivíduos nascidos entre 1978 e 1980, e zero caso contrário. Para fins de estimação, o trabalho tomou como referência as duas primeiras coortes, isto é, os indivíduos nascidos entre 1927 e 1932.

\section{Ciclos econômicos no Brasil contemporâneo}

\subsection{Ciclos econômicos e bem-estar social: evidências de estudos anteriores}

O período analisado no presente artigo compreende sete ciclos macroeconômicos, sendo que quatro são considerados de expansão, e três de recessão. A caracterização dos ciclos seguiu a metodologia dos trabalhos de Neri e Thomas (2000); Rocha (2003) e Justesen (2008), com algumas modificações, já que esses trabalhos utilizaram dados mensais, e, no presente estudo, se utiliza dados anuais. A descrição dos ciclos encontra-se no quadro a seguir:

Quadro 6

Descrição dos ciclos macroeconômicos

\begin{tabular}{|c|c|c|c|l|}
\hline Ciclo & Início & Final & Movimento & \multicolumn{1}{|c|}{ Fatos Relevantes (1) $^{\text {(1) }}$} \\
\hline 1 & 1984 & 1987 & Expansão & $\begin{array}{l}\text { Recuperação econômica após a crise da dívida } \\
\text { externa; Plano Cruzado; estabilização monetária } \\
\text { momentânea; políticas expansionistas. }\end{array}$ \\
\hline 2 & 1990 & 1993 & Desaceleração & $\begin{array}{l}\text { Plano Collor; contração monetária severa; } \\
\text { abertura econômica externa. }\end{array}$ \\
\hline 3 & 1994 & 1995 & Expansão & $\begin{array}{l}\text { Plano Real; atração de capitais externos; } \\
\text { expansão do consumo. }\end{array}$ \\
\hline 5 & 1996 & 1999 & Desaceleração & $\begin{array}{l}\text { Crises financeiras na Ásia e na Rússia; pressão } \\
\text { sobre taxa cambial sobre-valorizada; taxas de } \\
\text { juros crescentes. }\end{array}$ \\
\hline 6 & 2001 & 2003 & Desaceleração & $\begin{array}{l}\text { "Apagão"; crise na Argentina; pânico financeiro } \\
\text { pré-eleitoral. }\end{array}$ \\
\hline 7 & 2004 & 2008 & Expansão & $\begin{array}{l}\text { Estabilidade monetária e crescimento econômico } \\
\text { internacionais. }\end{array}$ \\
\hline
\end{tabular}

(1) Uma melhor descrição sobre as características e os principais fatos econômicos de cada ciclo podem ser encontrados no estudo de Neri e Thomas (2000).

Fonte: Elaboração própria a partir dos trabalhos de Neri \& Thomas (2000), Rocha (2003) e Justesen (2008). 
Um estudo empírico sobre a dinâmica da inflação e do desemprego durante as décadas de oitenta e de noventa, e suas conseqüências sobre os indicadores de desigualdade e de pobreza no país, foi realizado por Barros et al. (2000). Os autores verificam que enquanto a pobreza no Brasil está mais correlacionada com o desemprego, a desigualdade está mais correlacionada com a inflação. Contudo, o impacto do desemprego, tanto sobre a desigualdade como sobre a pobreza, decresceu ao longo da década de noventa, principalmente após entrar em vigor o Plano Real, em 1995. Já o impacto da inflação sobre esses dois indicadores tende a ser menor quanto maior for o seu valor, o que indica, segundo os autores, que a sociedade acaba por criar mecanismos institucionais para contornar os efeitos reais da inflação sobre a economia.

Barros et al. (2001) obtiveram resultados semelhantes. Segundo o seu trabalho, para toda a série analisada, a pobreza no Brasil é sensível a flutuações cíclicas de curto prazo, tais como a instabilidade macroeconômica. Analisando os determinantes imediatos da pobreza, os autores apontaram que o principal problema não é a escassez de recursos no Brasil, mas sim a desigualdade na sua distribuição entre as pessoas ${ }^{15}$. Os autores também observaram que os padrões de desigualdade, em uma ampla variedade de indicadores, mostraram-se estáveis em termos de patamares desde o final da década de setenta até o final da década de noventa.

Um estudo específico sobre o impacto dos choques macroeconômicos sobre o bem-estar individual na economia brasileira foi elaborado por Neri e Thomas (2000). Utilizando dados da Pesquisa Mensal de Emprego (PME), um painel rotativo de dados de trabalhadores brasileiros, de 1984 a 1999, os autores concluem, em primeiro lugar, que os choques provocam instabilidade sobre os rendimentos dos trabalhadores. As recessões afetam mais intensamente a renda dos mais ricos, mesmo que eles tenham melhores meios de se proteger das crises, mas os mais ricos tendem a ganhar mais com os períodos de crescimento. Os momentos de crescimento pró-pobre foram os anos que imediatamente sucederam planos de estabilização macroeconômica, como o plano Cruzado (1987) e o plano Real (1994). Em segundo lugar, no que diz respeito à taxa de pobreza, foi estimado que ela depende menos do ciclo macroeconômico do que das características individuais dos pobres, sobretudo no que diz respeito a sua escolaridade e qualificação profissional. Assim, os trabalhadores de baixo nível educacional tendem a empobrecer nos períodos de crise, mas não se recuperam totalmente nos períodos de crescimento, levando-os a

(15) Os determinantes mais específicos da desigualdade no Brasil já haviam sido estudados por Barros e Mendonça (1995b), em um trabalho empírico a partir da teoria do capital humano. Testando a importância de vários fatores sobre a desigualdade, tais como a segmentação do mercado de trabalho no país, tanto em termos institucionais, como em termos regionais, a discriminação por raça e gênero e os diferenciais de produtividade e de experiência dos trabalhadores, os autores concluíram que o principal fator que influencia a desigualdade salarial no país são os diferenciais de educação entre os trabalhadores. Isso ocorre tanto em termos de desigualdade no acesso à educação, como também em termos de sensibilidade do salário em função do nível educacional do trabalhador. 
um processo de empobrecimento progressivo. Em terceiro lugar, no que diz respeito ao emprego, observou-se que a taxa de desemprego tende a acompanhar o ciclo econômico. Todavia, não há uma correlação direta entre o desemprego e a pobreza no Brasil, tanto pelo papel do setor informal no mercado de trabalho, que absorve parte da mão-de-obra sobretudo nos períodos de recessão, como pelo papel dos mecanismos de seguro-desemprego, que ajudam o trabalhador a escolher melhor seu próximo emprego, nas épocas de expansão econômica.

No mesmo sentido do trabalho de Neri e Thomas (2000); Justesen (2008) estimou o impacto do crescimento de longo prazo e das flutuações cíclicas sobre os trabalhadores brasileiros, controlando por sua idade. O autor utilizou dados da PNAD de 1978 a 2002, e baseou seu estudo na observação do comportamento de uma série de indicadores de bem-estar ao longo do tempo, como participação no mercado de trabalho, taxa de desemprego e nível de salários. O autor concluiu que as recessões afetam principalmente os jovens em termos de participação no mercado de trabalho e de desemprego. Segundo o estudo, a taxa de desemprego dos jovens apresenta um crescimento menor nas crises, mas mantém-se em um patamar muito superior ao dos adultos. Por outro lado, o salário dos jovens tende a reduzir-se relativamente menos, criando uma situação de rigidez salarial que pode, inclusive, explicar as suas maiores taxas de desemprego.

\subsection{Comportamento dos Indicadores Sócio-Econômicos no Brasil (1987-2005): análise descritiva}

O comportamento dos principais indicadores socioeconômicos ao longo dos anos abordados, em termos de proporção da amostra, está representado no Gráfico 1:

Gráfico 1

Evolução dos indicadores sócio-econômicos, em porcentagem (1987-2005)

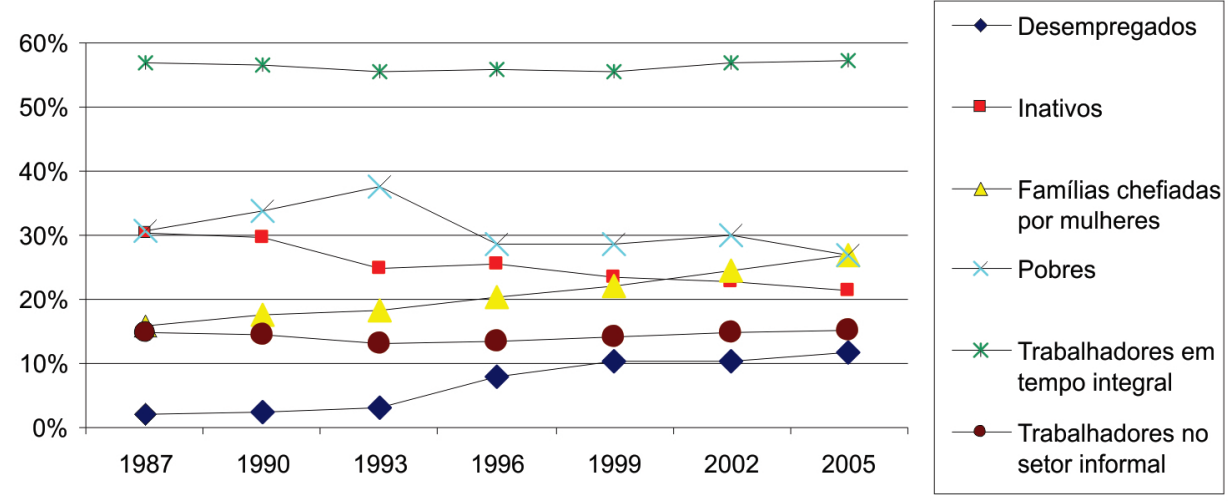

Fonte: Elaboração própria a partir de dados da PNAD. 
Como o Gráfico 1 mostra, no período estudado, a evolução da proporção de indivíduos pobres de 25 a 60 anos de idade no Brasil apresenta quatro trajetórias distintas, acompanhando os ciclos macroeconômicos.

Segundo Rocha (1992), particularmente em 1986, quando foi implantado o plano Cruzado, houve uma brusca redução da pobreza em todo o país. Isso se deve não apenas à política de estabilização monetária de congelamento de preços, mas também devido a políticas de abono salarial, de reajustes aos trabalhadores acima da inflação, o que proporcionou maiores ganhos para a base da distribuição de renda (famílias mais pobres). Contudo, de 1987 a 1993 a proporção de pobres apresentou trajetória crescente, o que pode explicada pelos sucessivos fracassos dos programas macroeconômicos de estabilização, pela explosão inflacionária, e pelo crescimento da desigualdade de rendimentos no país (Barros; Mendonça, 1995a).

O período de 1993-95 foi marcado pela estabilização econômica do país, com a implantação do plano Real. A estabilização provocou uma acentuada queda no percentual de pobres e uma evolução favorável dos rendimentos na base da distribuição de renda, reduzindo o hiato da renda (intensidade da pobreza), por três motivos. Primeiro, devido a um comportamento mais estável da dinâmica de preços dos alimentos. Segundo, devido à elevação relativa de preços dos bens relacionados aos setores comerciais e de prestação de serviços da economia, que empregam boa parte dos trabalhadores de menor renda do país. Terceiro, devido à elevação do salário mínimo em $42 \%$ em 1995, o que contribuiu positivamente principalmente para os benefícios previdenciários e assistenciais.

O período 1996-99, segundo Rocha (2003) representa o esgotamento do processo de redistribuição de renda provocado pela estabilização. Nesse período, a conjuntura macroeconômica brasileira esteve vulnerável a distúrbios financeiros externos, que provocaram situações de recessão e queda na renda per capita no país ${ }^{16}$, afetando mais intensamente os indivíduos com menor escolaridade. Do mesmo modo, o início da década de 2000 foi um período marcado pela freqüência de choques externos sobre a economia brasileira, tais como a crise energética (2001), a crise financeira na Argentina (início de 2002) e o temor de vulnerabilidade externa da economia brasileira (final de 2002).

Por fim, a partir de 2002 a situação voltou a se inverter. Como motivos que explicam essa queda na proporção de pobres no país, os estudos empíricos apontam os papéis da estabilidade monetária, que mantém o valor real dos rendimentos dos mais pobres, os quais não têm acesso a instrumentos financeiros para proteção, da elevação do valor real do salário mínimo (Rocha, 2006), da variação da composição demográfica das famílias, com o crescimento da proporção de membros adultos (Rocha, 2003; IPEA, 2006), da institucionalização de programas sociais focalizados

(16) De acordo com Ferreira et al. (2000), as respostas em termos de política econômica frente aos choques externos reforçaram os seus impactos em elevar os indicadores de pobreza no Brasil. 
nos mais pobres a partir da década de 90 (IPEA, 2006; Rocha, 2006), da redução na desigualdade salarial entre os trabalhadores, sobretudo a partir de 2001 (Rocha, 2003; IPEA, 2006), da quase universalização do acesso ao Ensino Fundamental, no final da década de 90 (Rocha, 2003), da aceleração do crescimento econômico a partir de 2003 (Rocha, 2006), e da política de valorização do salário mínimo (Barros et al., 2007), entre outros fatores.

A estabilização monetária obtida com o plano Real foi mantida, durante todo o período, mediante políticas restritivas, as quais elevaram a taxa de desemprego para um patamar perto de $10 \%$ a partir de 1999 . Também se observa uma sensível redução na proporção de inativos, que está relacionada à crescente participação feminina no mercado de trabalho, conforme já observado por Justesen (2008), um aumento da proporção de famílias chefiadas por mulheres, e um comportamento oscilatório da taxa de informalidade ${ }^{17}$.

A taxa de desemprego, que aumentou bruscamente após a implantação do Plano Real, atingiu trabalhadores de todas as idades, mas seu crescimento afetou sobretudo os mais jovens, conforme já observado pelo trabalho de Justesen (2008). Esse fenômeno atinge com maior intensidade os indivíduos mais jovens de todos os grupos demográficos, e esse efeito se fortaleceu ao longo do tempo. Nota-se uma explosão desse indicador a partir da década de meados da década de 1990, principalmente devido às mudanças metodológicas de cálculo do desemprego pela PNAD, conforme explicado por Dedecca (1998a). Contudo, não se pode ignorar o papel das políticas restritivas adotadas frente às oscilações macroeconômicas internacionais, como a crise asiática, em 1997, e a crise na Rússia, em 1998.

Nesses anos de análise, o percentual de inflação, medida pelo Índice de Preços ao Consumidor Acumulado, apresentou uma explosão até 1993, e a partir desse ano se estabilizou, com a implantação do Plano Real, em 1994. De 1996 a 2005, a inflação oscilou entre os patamares de cerca de $6 \%$ e de $12 \%$ ao ano, se acelerando nos períodos de recessão.

Por fim, os indicadores de política fiscal incluídos no modelo empírico apresentaram trajetórias distintas ao longo do período estudado. Os gastos sociais, isto é, o somatório de gastos do governo federal com saúde, saneamento, educação, cultura, assistência e previdência cresceram subitamente após a Constituição Federal de 1988, saltando de um patamar de 4\% do PIB em 1987 para 10\% em 1990, até se estabilizar em torno de $13 \%$ após o ano 2000. O superávit primário manteve uma trajetória crescente ao longo do período, convergindo assintoticamente para um nível próximo de $8 \%$ do PIB. Contudo, verificou-se um valor muito elevado e inexplicado pela literatura, para o ano de 1993, motivado, de acordo com os dados da Secretaria do Tesouro Nacional, por uma elevada arrecadação da União com Receitas de

(17) A proporção de trabalhadores no setor informal da economia é relativamente baixa, no presente trabalho, como conseqüência da delimitação da idade dos indivíduos da amostra a partir de 25 anos. Como se sabe, a informalidade atinge mais os trabalhadores mais jovens. 
Patrimônio e com Transferências Correntes. A evolução do gasto primário da União, por sua vez, manteve uma trajetória de crescimento ao longo do período da amostra, com oscilações em 1993 e 1999, nesse último caso, provocada pela introdução da política de metas de superávit primário pelo Ministério da Fazenda e pelo Banco Central.

Gráfico 2

Evolução dos indicadores fiscais (1987-1990)

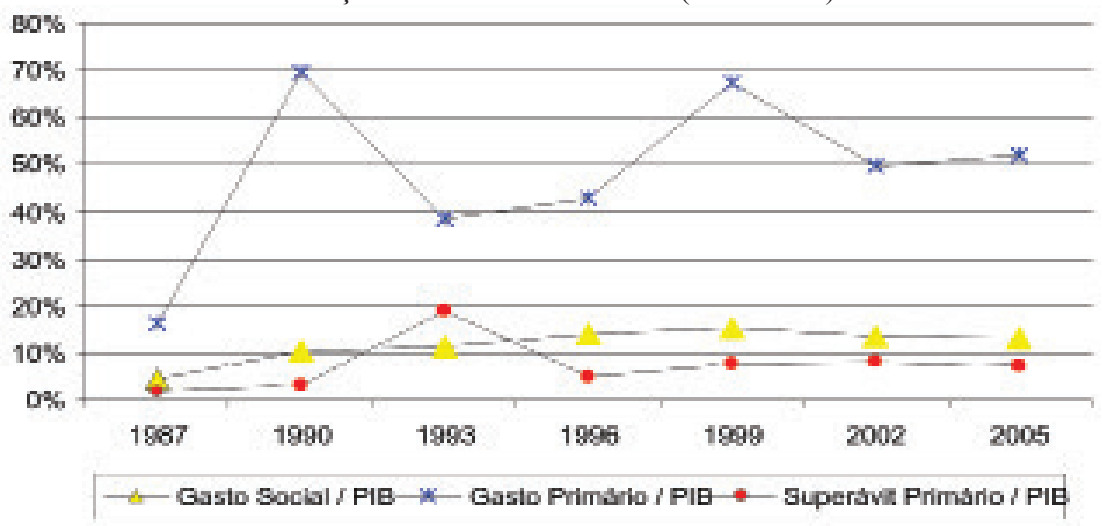

Fonte: Elaboração própria a partir de dados da Secretaria do Tesouro Nacional.

\section{Análise dos resultados}

Os resultados das estimações econométricas dos modelos empíricos encontram-se na Tabela abaixo. Todos foram estimados pela metodologia de modelos de regressão logística.

Tabela 2

Resultados dos modelos de regressão logística de pobreza ${ }^{(1)}$

\begin{tabular}{|c|c|c|c|c|c|c|}
\hline Variável & Modelo 1 & Modelo 2 & Modelo 3 & Modelo 4 & Modelo 5 & Modelo 6 \\
\hline \multirow{2}{*}{ Constante } & $0.828 * * *$ & & $-0.844 * * *$ & 0.106 & $-2.126 * * *$ & $-2.109 * * *$ \\
\hline & $(0.057)$ & $(0.095)$ & $(0.110)$ & $(0.231)$ & $(0.097)$ & $(0.217)$ \\
\hline \multirow{2}{*}{ Desempregado } & $0.946 * * *$ & $0.794 * * *$ & $0.805 * * *$ & $0.842 * * *$ & $0.802 * * *$ & $0.840 * * *$ \\
\hline & $(0.012)$ & $(0.013)$ & $(0.013)$ & $(0.013)$ & $(0.013)$ & $(0.013)$ \\
\hline \multirow{2}{*}{ Inativo } & $0.322 * * *$ & $0.072 * * *$ & $0.081 * * *$ & $0.099 * * *$ & $0.085^{* * *}$ & $0.098 * * *$ \\
\hline & $(0.007)$ & $(0.011)$ & $(0.011)$ & $(0.011)$ & $(0.011)$ & $(0.011)$ \\
\hline \multirow{2}{*}{ Anos de estudo } & & & $-0.200 * * *$ & $-0.200 * * *$ & $-0.185 * * *$ & $-0.176 * * *$ \\
\hline & $(0.001)$ & $(0.001)$ & $(0.001)$ & $(0.001)$ & $(0.002)$ & $(0.002)$ \\
\hline \multirow{2}{*}{ Idade } & $0.027 * * *$ & $0.074 * * *$ & $0.071 * * *$ & $0.083 * * *$ & $0.088 * * *$ & $0.083 * * *$ \\
\hline & $(0.003)$ & $(0.004)$ & $(0.004)$ & $(0.005)$ & $(0.004)$ & $(0.005)$ \\
\hline \multirow{2}{*}{ Idade2 } & & & $-0.001 * * *$ & $-0.001 * * *$ & $-0.001 * * *$ & $-0.001 * * *$ \\
\hline & $(0.000)$ & $(0.000)$ & $(0.000)$ & $(0.000)$ & $(0.000)$ & $(0.000)$ \\
\hline \multirow{2}{*}{$\begin{array}{l}\text { Interação entre expansão } \\
\text { e chefia feminina }\end{array}$} & & & -0.026 & -0.015 & & \\
\hline & & & $(0.022)$ & $(0.022)$ & & \\
\hline
\end{tabular}


Tabela 2 - Continuação

\begin{tabular}{|c|c|c|c|c|c|c|}
\hline Variável & Modelo 1 & Modelo 2 & Modelo 3 & Modelo 4 & Modelo 5 & Modelo 6 \\
\hline \multirow{2}{*}{$\begin{array}{l}\text { Interação entre expansão } \\
\text { e raça negra }\end{array}$} & & & -0.024 & -0.017 & & \\
\hline & & & $(0.017)$ & $(0.017)$ & & \\
\hline \multirow{2}{*}{$\begin{array}{l}\text { Interação entre expansão } \\
\text { e escolaridade } 0 \text { a } 3\end{array}$} & & & $0.372 * * *$ & $0.865 * * *$ & & \\
\hline & & & $(0.040)$ & $(0.089)$ & & \\
\hline \multirow{2}{*}{$\begin{array}{l}\text { Interação entre expansão } \\
\text { e escolaridade } 4 \text { a } 7\end{array}$} & & & $0.479 * * *$ & $0.978 * * *$ & & \\
\hline & & & $(0.038)$ & $(0.088)$ & & \\
\hline \multirow{2}{*}{$\begin{array}{l}\text { Interação entre expansão } \\
\text { e escolaridade } 8 \text { a } 10\end{array}$} & & & $0.673 * * *$ & $1.178 * * *$ & & \\
\hline & & & $(0.040)$ & $(0.089)$ & & \\
\hline \multirow{2}{*}{$\begin{array}{l}\text { Interação entre expansão } \\
\text { e escolaridade } 11 \text { a } 14\end{array}$} & & & $0.464 * * *$ & $0.975 * * *$ & & \\
\hline & & & $(0.040)$ & $(0.088)$ & & \\
\hline \multirow{2}{*}{$\begin{array}{l}\text { Ano no ciclo de } \\
\text { expansão }\end{array}$} & & & $-0.216^{* * *}$ & $-0.592 * * *$ & & \\
\hline & & & $(0.012)$ & $(0.051)$ & & \\
\hline \multirow{2}{*}{$\begin{array}{l}\text { Interação entre recessão } \\
\text { e chefia feminina }\end{array}$} & & & & & $-0.040 * *$ & 0.026 \\
\hline & & & & & $(0.022)$ & $(0.022)$ \\
\hline \multirow{2}{*}{$\begin{array}{l}\text { Interação entre recessão } \\
\text { e raça negra }\end{array}$} & & & & & $-0.057 * * *$ & 0.006 \\
\hline & & & & & $(0.017)$ & $(0.017)$ \\
\hline \multirow{2}{*}{$\begin{array}{l}\text { Interação entre recessão } \\
\text { e escolaridade } 0 \text { a } 3\end{array}$} & & & & & $0.203 * * *$ & $1.019 * * *$ \\
\hline & & & & & $(0.019)$ & $(0.054)$ \\
\hline \multirow{2}{*}{$\begin{array}{l}\text { Interação entre recessão } \\
\text { e escolaridade } 4 \text { a } 7\end{array}$} & & & & & $0.177 * * *$ & $0.967 * * *$ \\
\hline & & & & & $(0.017)$ & $(0.052)$ \\
\hline \multirow{2}{*}{$\begin{array}{l}\text { Interação entre recessão } \\
\text { e escolaridade } 8 \text { a } 10\end{array}$} & & & & & $0.222 * * *$ & $0.985 * * *$ \\
\hline & & & & & $(0.019)$ & $(0.051)$ \\
\hline \multirow{2}{*}{$\begin{array}{l}\text { Interação entre recessão } \\
\text { e escolaridade } 11 \text { a } 14\end{array}$} & & & & & $-0.082 * * *$ & $0.653 * * *$ \\
\hline & & & & & $(0.020)$ & $(0.049)$ \\
\hline \multirow{2}{*}{$\begin{array}{l}\text { Ano no ciclo de } \\
\text { recessão }\end{array}$} & & & & & $0.044 * * *$ & $-0.315^{* * *}$ \\
\hline & & & & & $(0.004)$ & $(0.021)$ \\
\hline \multirow{2}{*}{ IPCA } & & & & $-0.027 * * *$ & & 0.008 \\
\hline & & & & $(0.007)$ & & $(0.006)$ \\
\hline \multirow{2}{*}{ Gasto social } & & & & $-18.256^{* * *}$ & & $-20.082 * * *$ \\
\hline & & & & $(1.497)$ & & $(1.104)$ \\
\hline \multirow{2}{*}{ Gasto primário } & & & & $0.451 * *$ & & $4.254 * * *$ \\
\hline & & & & $(0.190)$ & & $(0.346)$ \\
\hline \multirow{2}{*}{ Selic real } & & & & 0.000 & & $-0.004 * * *$ \\
\hline & & & & $(0.000)$ & & $(0.001)$ \\
\hline \multirow{2}{*}{ Superávit primario } & & & & $5.487 * * *$ & & $7.122 * * *$ \\
\hline & & & & $(1.174)$ & & $(0.933)$ \\
\hline N. Obs. & 985669 & 983278 & 983278 & 983278 & 983278 & 983278 \\
\hline
\end{tabular}

(1) O teste de Hausman indicou endogeneidade das variáveis dasempregado e inativo. Contudo, como a eliminação dessas variáveis dos modelos não afetou a estimação das variáveis de interesse, isto é, os resultados corrigidos e não corrigidos não são estatisticamente diferentes, os modelos foram mantidos em sua forma normal. Graças ao tamanho da amostra (mais de 980 mil observações), as variáveis podem ser consideradas assintoticamente normais. Essa hipótese foi confirmada pelo teste ShapiroFrancia. A heteroscedasticidade dos resíduos foi descartada de acordo com os testes de White, BreuschPagan e Szroeter.

*** Variável significativa a 1\%; ** Variável Significativa a 5\%; * Variável Significativa a 10\%.

Fonte: Elaboração própria. Os parâmetros das demais variáveis encontram-se em tabela em anexo. 
De acordo com o modelo simples de capital humano (Modelo 1), no qual a pobreza é explicada em função da situação do indivíduo no mercado de trabalho, de sua qualificação e de sua idade, os resultados obtidos estão de acordo com o esperado, dada a bibliografia estudada. A pobreza está positivamente relacionada às situações de desemprego e de inatividade e negativamente relacionada aos anos de estudo, variável utilizada como proxy para a qualificação do trabalhador. No que diz respeito à idade do trabalhador, variável utilizada como proxy para sua experiência no mercado de trabalho, esse indicador está positivamente relacionado à pobreza, mas seu termo ao quadrado é negativo. Isso significa que os trabalhadores mais jovens são mais pobres, e, conforme vão adquirindo experiência, tendem a sair da pobreza com uma probabilidade sempre decrescente ao longo dos anos de vida.

A inclusão de novas variáveis no modelo de capital humano não muda a significância e o sinal dessas variáveis mais básicas. O que se nota é a suavização da inclinação dessas variáveis, sobretudo no que diz respeito à inatividade e ao nível de educação do indivíduo. Em relação à posição na ocupação, verificou-se que os trabalhadores informais têm maior probabilidade de serem pobres em relação aos formalizados, e os empregadores e os trabalhadores em tempo integral, isto é, que trabalham pelo menos trinta horas semanais, têm menor probabilidade de ser pobres em relação aos seus contrários (respectivamente, trabalhadores empregados ou por conta própria e em regime de trabalho parcial). Esses resultados estão de acordo com os demais estudos empíricos semelhantes, e se mantiveram em todos os modelos seguintes do presente trabalho.

As variáveis referentes aos setores de ocupação, unidades da federação, raça e gênero, em todas as especificações adotadas, têm os sinais esperados de acordo com a literatura (Barros e Mendonça, 1995b; Dedecca, 1998b, 2005; Rocha, 2003; Mattos, 2005).

Por fim, no que diz respeito às coortes, verificou-se que os indivíduos nascidos há mais tempo tendem a ser menos pobres, em todos os anos da amostra. As coortes onze e doze, que incluem os indivíduos nascidos entre 1959 e 1962, não foram significantes, e, a partir da coorte treze, todas as demais estão positivamente relacionadas à pobreza. Contudo, esse resultado se mostrou muito sensível à introdução das variáveis de interesse, tanto de ciclos como de políticas macroeconômicas, no modelo.

De acordo com a bibliografia estudada, a conjuntura macroeconômica exerce efeitos diferenciados sobre os agentes econômicos de acordo com suas características. Em termos econométricos, isso significa dizer que o efeito parcial, ou a elasticidade da pobreza em relação às características dos indivíduos não depende apenas dessas características, mas também da magnitude de um indicador de ciclo econômico. Por isso, para analisar quais grupos sociais foram mais beneficiados ou 
prejudicados pelos ciclos econômicos, tanto os de expansão como os de desaceleração ou recessão, o presente trabalho usa variáveis dummy de interação entre os grupos e os ciclos. Assim, foram tomados como categorias de referência os grupos de sexo da chefia da família, raça e escolaridade identificados pelos estudos anteriores como sendo os de menor probabilidade de ser pobre (homens, brancos e de 15 anos de estudo ou mais), e criou-se variáveis iguais a um quando o indivíduo pertence a uma das categorias identificadas como de maior vulnerabilidade à pobreza em um ano em que o ciclo macroeconômico é de recessão ou de expansão, e zero caso contrário. $\mathrm{O}$ trabalho conta, portanto, com 14 variáveis para medir os efeitos diferenciados dos ciclos econômicos sobre os indivíduos: quatro grupos educacionais, sexo do chefe da família, raça e posição do ano no ciclo, como forma de se mensurar o impacto do tamanho do ciclo econômico sobre o bem-estar dos indivíduos, para os momentos macroeconômicos de expansão e de recessão.

A inclusão do vetor de variáveis indicativas de ciclos macroeconômicos de expansão trouxe observações muito importantes à análise do seu impacto sobre os diferentes grupos demográficos. Em primeiro lugar, os ciclos de expansão não têm impacto significante sobre as famílias chefiadas por mulheres ${ }^{18}$, em relação aos membros de famílias chefiadas por homens. Em segundo lugar, o efeito do crescimento sobre os indivíduos negros é insignificante, em comparação com os indivíduos brancos. Terceiro, todos os grupos de escolaridade abaixo dos quinze anos de estudo são prejudicados, mas sem nenhuma lógica crescente ou decrescente entre eles, isto é, não é possível afirmar se os de mais anos de estudo são mais ou menos prejudicados. Quarto, a posição do ano no ciclo tende a reduzir a probabilidade de ser pobre, ou seja, o impacto do ciclo é crescente ao longo dos seus anos. Por fim, todas as coortes de grupo de idade tornaram-se negativamente correlacionadas com a pobreza, mas os mais velhos pareceram se beneficiar mais do que os mais jovens.

A inclusão dos indicadores de política econômica reduziu os impactos dos ciclos de expansão sobre as desigualdades de coorte. Nesse último caso, o efeito sobre os mais jovens tornou-se não-significante. Por outro lado, ampliou-se o impacto negativo sobre os grupos de escolaridade. A taxa de inflação e a proporção de gastos sociais da União em relação ao PIB apresentaram relação negativa com a pobreza, enquanto que a taxa real de juros não foi significante, e as proporções de gastos primários e de superávit primário da União em relação ao PIB se mostraram positivamente relacionados com a pobreza. As regressões mostraram, em alguns casos, valores extremos para os gastos sociais, o gasto primário e o superávit primário. Todavia, é importante observar que o impacto dos três indicadores de política fiscal deve ser analisado conjuntamente, já que foram construídos com base em um mesmo

(18) Destaca-se que, apesar de as coortes terem sido construídas de acordo com a variável "mulher”, a sua interação com os ciclos macroeconômicos foi realizada com a variável de chefia familiar por mulher, já que os dados de pobreza aqui utilizados foram construídos de acordo com a renda das famílias, e não dos indivíduos. 
conjunto de dados. Ou seja, os resultados obtidos podem refletir o fato de que, apesar do superávit primário e os gastos primários, incluindo o gasto social da União, serem financiados também pela arrecadação tributária sobre a renda das famílias, os gastos sociais são a alocação que melhor devolve os recursos à população necessitada, reduzindo diretamente a sua propensão à pobreza.

Em relação ao comportamento inesperado da taxa de inflação, que pareceu reduzir a probabilidade de se ser pobre no país, ele pode ser explicado de acordo com o raciocínio descrito por Barros et al. (2000). Segundo o autor, a taxa de inflação não acompanha, de um modo geral, os ciclos de negócios no Brasil, isto é, tem um comportamento íngreme até 1994, e se torna relativamente estável a partir de 1995, havendo, portanto, pouca variabilidade em relação ao desempenho macroeconômico do país. Outra hipótese é a sua possível correlação temporal com o gasto social da União, de modo que, em primeiro lugar, a década de oitenta e o início da década de noventa foram períodos marcados pela explosão inflacionária e da pobreza no Brasil. Contudo, particularmente nos anos oitenta, anteriores à promulgação da Constituição Federal de 1988, que estabeleceu novos deveres das esferas de governo brasileiras em relação ao bem-estar social, a proporção de gastos sociais - isto é, a proporção da soma de gastos com educação, cultura, saúde, saneamento, assistência e previdência - sobre o PIB era muito baixa no país. Por isso, parte do efeito da inflação sobre o crescimento da pobreza pode estar sendo capturado pela variável de gastos sociais. Contudo, após o Plano Real e a estabilização de preços, a inflação pode ser interpretada até mesmo como um indicador de instabilidade financeira internacional, mas seus efeitos sobre a pobreza são ambíguos.

As recessões prejudicam menos as famílias de chefe feminino e os indivíduos de raça negra, em relação às demais. Por outro lado, para os grupos de escolaridade, prejudicam mais os grupos de escolaridade abaixo dos onze anos de estudo, mas em grau menor do que nos períodos de expansão. Além disso, agora a posição do ano no ciclo é positiva, de modo que a probabilidade de ser pobre aumenta proporcionalmente ao tamanho do ciclo. No que diz respeito ao impacto sobre as coortes, nota-se que os indivíduos mais velhos se saem melhor, pelo menos até a coorte quinze, enquanto que os mais jovens estão mais correlacionados com a pobreza.

A inclusão dos indicadores de política econômica tirou a significância das coortes mais jovens e do impacto do ciclo econômico sobre as famílias chefiados por mulheres e sobre os negros. Por outro lado, aumentou o impacto negativo sobre os grupos de escolaridade mas, mesmo assim, em magnitude inferior à verificada nas expansões. Nesse caso, a posição do ciclo é negativa, de modo que os choques se dissipam ao longo do tempo, o que pode ser um indicador de que as reações políticas aos ciclos recessivos tenham maior impacto sobre a pobreza do que os próprios 
ciclos. As políticas fiscais assumem o mesmo efeito que nas expansões, ao passo que a inflação se torna não-significante, o que pode ser um efeito da hiper-inflação até 1993, e os juros reais parecem estar negativamente relacionados com a pobreza.

\section{Considerações finais}

Dentre as conclusões gerais obtidas pela análise empírica do presente estudo, destaca-se a evidência de que há em todos os períodos estudados uma tendência de convergência, ainda que lenta, das taxas de pobreza dos negros em relação aos brancos e das famílias chefiadas por mulheres em relação as demais. Esse processo é mais intenso nos períodos de recessão. Também se verifica um empobrecimento relativo dos trabalhadores de dez anos de educação ou menos, e esse efeito é mais forte nos períodos de expansão. Essa observação levanta a possibilidade de uma mudança tecnológica direcionada como consequência da reestruturação produtiva das empresas no período analisado. Essa hipótese está relacionada à importação de tecnologia por parte das empresas brasileiras como forma de se manterem competitivas nos mercados globalizados após a abertura econômica, assim também como conseqüência da instalação de novas empresas transnacionais no país. De acordo com essa hipótese, as empresas, durante as expansões macroeconômicas, tenderam a se intensificar cada vez mais em mão-de-obra qualificada e em capital físico, elevando a sua produtividade marginal e, consequentemente, a remuneração desses fatores, em um processo de acordo com as teorias desenvolvidas por Acemoglu (1998, 2002), Krusell et al. (2000) e Aghion et al. (2002).

Verifica-se que os ciclos econômicos recessivos afetam mais intensamente os indivíduos de menor educação. Por outro lado, o melhor desempenho macroeconômico é viesado para os indivíduos de maior escolaridade. Isto vai ao encontro da conclusão encontrada pelos trabalhos de Barros e Mendonça (1995a) e de Neri e Thomas (2000), que utilizaram outros métodos empíricos e outras bases de dados para investigar o mesmo tema. Além disso, notou-se que, em geral, os negros, os de mais idade e as famílias chefiadas por mulheres tendem a se sair melhor do que os seus opostos nesses períodos, mas, nesse caso, suas significâncias dependem muito das variáveis incluídas nos modelos, isto é, a pobreza é mais relacionada a outras variáveis.

Os períodos de expansão econômica tendem a beneficiar mais os indivíduos negros, de maior idade e com mais escolaridade. Em relação aos componentes idade e escolaridade, esse resultado corrobora a bibliografia estudada que sugere que o crescimento econômico pode ser viesado para os indivíduos mais qualificados ${ }^{19}$, como mostraram os modelos em nível individual, de acordo com uma série de mecanismos, dois quais dois se destacam como objetos de futura investigação empírica.

(19) Por exemplo, Cutler e Katz (1991); Barros e Mendonça (1995a) e Neri e Thomas (2000). 
Primeiro, a concentração de renda nos períodos de recessão. No caso brasileiro, esse fenômeno foi marcante na crise que seguiu o Plano Collor, isto é, até 1993. Isso, de acordo com a teoria do crescimento econômico pró-pobre, tenderia a limitar o impacto do crescimento sobre o bem-estar dos indivíduos com mais privações na economia.

Segundo, um processo de histerese no mercado de trabalho, segundo a qual, conforme descrito por Bonelli e Ramos (1993), os trabalhadores menos qualificados perdem emprego nas recessões com maior probabilidade do que os mais qualificados, e não conseguem se recuperar nas expansões, devido a motivos ligados à mudança tecnológica e as estratégias das empresas empregadoras. Por isso, mesmo que parte da bibliografia estudada aponte ganhos de renda individual para todos os trabalhadores nos períodos de expansão - e, segundo Neri e Thomas (2000), principalmente após os programas de estabilização monetária - os trabalhadores menos qualificados podem estar perdendo oportunidades de empregos durante as fases ascendentes do ciclo econômico.

Em relação às coortes de anos de nascimento, observa-se que os indivíduos nascidos há mais tempo têm sempre menor probabilidade de serem pobres do que os mais jovens. Inclusive, as recessões parecem atingir mais intensamente os trabalhadores mais jovens, como já havia sido argumentado pelo trabalho de Justesen (2008). Todavia, a inclusão das variáveis de política macroeconômica parece retirar boa parte desse efeito, o que pode significar que essas políticas afetam mais os mais jovens.

No que diz respeito às políticas, observou-se que o gasto social ajuda a segurar os indicadores de pobreza ${ }^{20}$, já que representa gastos com serviços públicos diretamente associados ao uso pelas pessoas mais carentes - principalmente no que diz respeito aos setores de educação, saúde, saneamento e assistência social. Contudo, o gasto público federal total não apresenta esse efeito. Por outro lado, a política fiscal contracionista, mensurada em termos de superávit primário, tende a reduzir a renda das famílias e elevar a pobreza, enquanto que o impacto da inflação tende a ser de mesma natureza, de maneira mais ambígua, já que os resultados podem estar influenciados pelo momento de hiperinflação que se prolongou até 1994.

Portanto, sugere-se que o ajuste fiscal, quando necessário, deve ser realizado de maneira que não prejudique os mais pobres, isto é, que não tribute as transações e os bens mais associados à população pobre, e não corte os gastos com os serviços públicos em relação aos quais os pobres são mais dependentes. No caso brasileiro, em que a relação direta entre o superávit primário e a probabilidade de ser pobre é significativa, isso implica que o modo pelo qual a poupança pública é obtida deve ser repensado. Isto é, cortes de gastos sociais e de investimentos em capital devem

(20) Isso está de acordo com os trabalhos de Lustig (2000) e Ferreira et al. (2000). 
ser evitados, assim como aumentos de impostos sobre o consumo de bens básicos pelas famílias.

A taxa Selic de juro real, por sua vez, parece estar negativamente relacionada à pobreza, mas esse resultado deve ser interpretado com muito cuidado. Talvez esteja refletindo algum tipo de exclusão financeira na economia brasileira, nos moldes previstos por Lustig (2000). Isto é, o aumento de juros restringe o crédito, e conseqüentemente o bem-estar, apenas de quem tem acesso ao crédito, e esse não é o caso da maioria das famílias pobres brasileiras. Por outro lado, a taxa de juros pode ser o fator macroeconômico que explica a persistência dos choques sobre o setor industrial brasileiro, já que esse é um setor estruturalmente dependente de crédito para o financiamento de investimentos e do próprio fluxo de caixa das empresas. Contudo, como a maior parte dos pobres brasileiros encontra-se empregada no setor de serviços, que hipoteticamente compreende empresas menores, de alto grau de informalidade e menor acesso ao crédito, isso pode também explicar em parte o resultado dos modelos aqui estimados. Por fim, a taxa de juros, sobretudo após o Plano Real, pode estar relacionada ao controle da inflação, a qual, segundo Ferreira et al. (2000), afeta mais intensamente os rendimentos dos mais pobres. Ressalta-se que todas essas hipóteses aqui levantadas não foram testadas no presente trabalho, pois estão além de seus objetivos. Contudo, todas elas merecem testes adicionais para futuras linhas de pesquisa.

Em relação às políticas sociais, o presente trabalho destaca a importância dos sistemas de assistência e seguridade social para manter estável o padrão de vida das famílias mais pobres ao longo de choques macroeconômicos negativos e ajustes políticos restritivos, corroborando a literatura estudada. Como tema para futura investigação empírica, sugere-se a estimação dos impactos desagregados dos gastos sociais, principalmente diferenciando-se os gastos com assistência e previdência social e os investimentos em educação, saúde e saneamento básico, que interferem diretamente na acumulação de capital humano, e, por conseguinte, melhorando a qualidade da força de trabalho da economia. Por fim, o presente trabalho ressaltou a importância da escolaridade das pessoas para a sua vulnerabilidade à pobreza nos períodos de desacelerações macroeconômicas. Por isso, investimentos públicos em educação, tanto no que diz respeito a sua universalização na população, como também em melhorias de sua qualidade, são fundamentais para restringir os impactos adversos dos ciclos econômicos sobre o bem-estar das famílias.

\section{Referências bibliográficas}

AASSVE, A.; APRINO, B. Dynamic multi-level analysis of households' living standards and poverty: evidence from Vietnam. Colchester: ISER, 2007. 43p. (Working paper, n. 2007-10). 
ACEMOGLU, D. Why do new technologies complement skills? Directed technical change and wage inequality. Quarterly Journal of Economics, 113, p. 1055-1090, 1998.

. Directed technical change. Review of Economic Studies, 69, p. 781-809, 2002.

. Patterns of skill premia. Review of Economic Studies, 70, p. 199-230, 2003 a.

. Labor- and capital-augmenting technical change. Journal of European Economic Association, v. 1, n. 1, p. 1-37, 2003 b.

. Equilibrium bias of technology. Econometrica, v. 75, n. 5, p. 1371-1410, 2007.

. Introduction to modern economic growth. Princeton University Press, 2011.

; ZILIBOTTI, F. Productivity differences. Quarterly Journal of Economics, v. 116, n. 2, p. 563-606, 2001.

AGHION, P.; HOWITT, P.; VIOLANTE, G., L. General purpose technology and wage inequality. Journal of Economic Growth, v. 7, n. 4, p. 315-345, Dec. 2002.

ANTMAN, F.; MCKENZIE, D. J. Earnings mobility and measurement error: a pseudopanel approach. Washington, DC.: World Bank, 2005. 36p. (Policy Research Working Paper, n. 3745).

BARROS, R. P.; CORSEUIL, C.; MENDONÇA, R.; REIS, M. C. Poverty, inequality and macroeconomic instability. Rio de Janeiro: IPEA, 2000. 14p. (Texto para Discussão, n. 750).

; HENRIQUES, R.; MENDONÇA, R. A estabilidade inaceitável: desigualdade e pobreza no Brasil. Rio de Janeiro: IPEA, 2001. 24 p. (Texto para discussão, n. 800).

; MENDONÇA, R. A evolução do bem-estar, pobreza e desigualdade no Brasil ao longo das últimas três décadas: 1960/90. Pesquisa e Planejamento Econômico, Rio de Janeiro, v. 25, n. 1, p. 115-164, 1995a.

; MENDONÇA, R. Os determinantes da desigualdade no Brasil. Brasilia: IPEA, 1995b. 63p. (Texto para Discussão, n. 377).

et al. (Org.). Desigualdade de renda no Brasil: uma análise da queda recente. Brasília: IPEA, 2007. v. 2.

BLANK, R. M.; BLINDER, A. S. Macroeconomics, income distribution, and poverty. In: DANZIGER, S. H.; WEINBERG, D. H. (Ed.). Fighting poverty: what works and what doesn't. Cambridge, Mass.: Harvard University, 1986. p. 180-208.

; CARD, D. Poverty, income distribution and growth: are they still connected? Brookings Papers on Economic Activity, Washington, DC., n. 2, p. 285- 325, Aug. 1993.

BONELLI, R.; RAMOS, L. Distribuição de renda no Brasil: avaliação das tendências de longo prazo e mudanças na desigualdade desde meados dos anos 70. Revista de Economia Política, São Paulo, v. 13, n. 2, p. 76-97, 1993. 
BOURGUIGNON, F.; GOH, C. Estimating individual vulnerability to poverty with pseudopanel data. Washington, DC.:World Bank, 2004. 17p. (Policy Research Paper, n. 3375).

BRADY, D. Reconsidering the divergence between eldery, child and overall poverty. Research on Aging, Thousand Oaks, Calif., v. 26, n. 5, p. 487-510, 2004.

CAMERON, A. C.; TRIVEDI, P. K. Microeconometrics - Methods and applications. Cambridge University Press, 2005.

CORSEUIL, C. H.; FOGUEL, M. N. Uma sugestão de deflatores para rendas obtidas a partir de algumas pesquisas domiciliares do IBGE. Rio de Janeiro: IPEA, 2002. 13p. (Texto para Discussão, n. 897).

CUTLER, D.; KATZ, L. Macroeconomic performance and the disadvantaged. Brookings Papers on Economic Activity, Washington, DC., n. 2, p. 1-106, 1991.

DEATON, A. Measuring poverty. Princeton: Princeton University, Research Program in Development Studies, 2004. 21p. (Working Papers, n. 230).

DEDECCA, C. S. A Pesquisa Nacional por Amostra de Domicílios - PNAD - Síntese Metodológica. Revista Brasileira de Estudos Populacionais, Brasília, v. 15 n. 2, p. 103-114, 1998a.

O desemprego e seu diagnóstico hoje no Brasil. Revista de Economia Política, São Paulo, v. 18, n. 1, p. 99-118, 1998 b.

Notas sobre a evolução do mercado de trabalho no Brasil. Revista de Economia Política, São Paulo, v. 25 n. 1, p. 94-111, 2005.

FERREIRA, F.; PRENNUSHI, G.; RAVALLION, M. Protecting the poor from macroeconomic shocks: an agenda for action in a crisis and beyond. Washington, DC.: World Bank, 2000. 28p. (Working Paper, n. 2160).

FREEMAN, R. B. The rising tide lifts...? Cambridge, Mass.: NBER, 2001. 40 p. (Working Paper, n. 8155).

GAFAR, J. Growth, inequality and poverty in selected Caribbean and Latin American countries, with emphasis on Guyana. Journal of Latin American Studies, Cambridge, v. 30, pt. 3, p 591-617, Oct.1998.

HAVEMAN, R.; SCHWABISH, J. Macroeconomic performance and the poverty rate: a return to normalcy? Madison, Wis.: University of Wisconsin, Institute for Research on Poverty, 1999. 27p. (Discussion Paper, n. 1187-99).

HINES JR, J. R.; HOYNES, H.; KRUEGER, A. B. Another look at whether a rising tide lifts all boats. Cambridge, Mass.: NBER, 2001. 69p. (Working Paper, n. 8412).

HOYNES, H., PAGE, M.; STEVENS, A. Poverty in America: trends and explanations. Cambridge, Mass.: NBER, 2005. (Working Paper, 11681).

IPEA. Sobre a recente queda da desigualdade de renda no Brasil. IPEA. 2006. (Nota Técnica, n. 09). 
JUSTESEN, M. Is the window of opportunity closing for Brazilian youth? Labor market trends and business cycle effects. Washington, DC.: World Bank, 2008. 49p.

KRUSELL, P.; OHANIAN, L.; RIOS-RULL, J. V.; VIOLANTE, G. L. Capital skill complementarity and inequality: a macroeconomic analysis. Econometrica v. 68, p. 10291054, 2000.

LUSTIG, N. Crises and the poor: socially responsible macroeconomics. Washington, DC.: Inter-American Development Bank, Susteinable Development Department, 2000. 36p. (Working Paper, n. 108).

MALONEY, W. F.; CUNNINGHAM, W. V.; BOSCH, M. The distribution of income shocks during crises: an application of quantile analysis to Mexico, 1992-95. The World Bank Economic Review, Washington, DC., v. 18, n. 2, p. 155-174, 2004.

MATTOS, F. A. M. Aspectos históricos e metodológicos da evolução recente do perfil distributivo brasileiro. São Paulo em Perspectiva, São Paulo, v. 19 n. 2, p. 135-149, abr.jun. 2005 .

NERI, M. C.; THOMAS, M. R. Macro shocks and microeconomic instability: an episodic analysis of booms and recessions. Rio de Janeiro: FGV, EPGE, 2000. 18p. (Ensaios Econômicos, n. 391).

OKUN, A. The gap between actual and potential output. In: OKUN, A. M. (Ed.). The battle against unemployment. New York: W. W. Norton, 1965. 204p.

Upward mobility in a high-pressure economy. Brookings Papers on Economic Activity, Washington, DC., n. 1, p. 207-252, 1973.

ROCHA, S. Pobreza no Brasil: parâmetros básicos e resultados empíricos. Pesquisa e Planejamento Econômico, Rio de Janeiro, v. 22, n. 3, p. 541-560, dez. 1992.

Do consumo observado à linha de pobreza. Pesquisa e Planejamento Econômico, Rio de Janeiro, v. 27 n. 2, p. 313-352, 1997.

. Pobreza no Brasil: afinal, do que se trata? Rio de Janeiro: FGV, 2003. 244p.

. Pobreza no Brasil: algumas evidências empíricas com base na PNAD 2004. Nova

Economia, Belo Horizonte, v. 16, n. 2, p. 265-299, 2006.

SOARES, S. S. D. Metodologias para estabelecer a linha de pobreza: objetivas, subjetivas, relativas, multidimensionais. Brasilia: IPEA, 2009. 50p. (Texto para Discussão, n. 1381).

WOOLDRIDGE, J. M. Econometric analysis of cross section and panel data. Ed. Thomson, 2006 . 
Ricardo Agostini Martini / Ana Maria Hermeto / Frederico G. Jayme Jr.

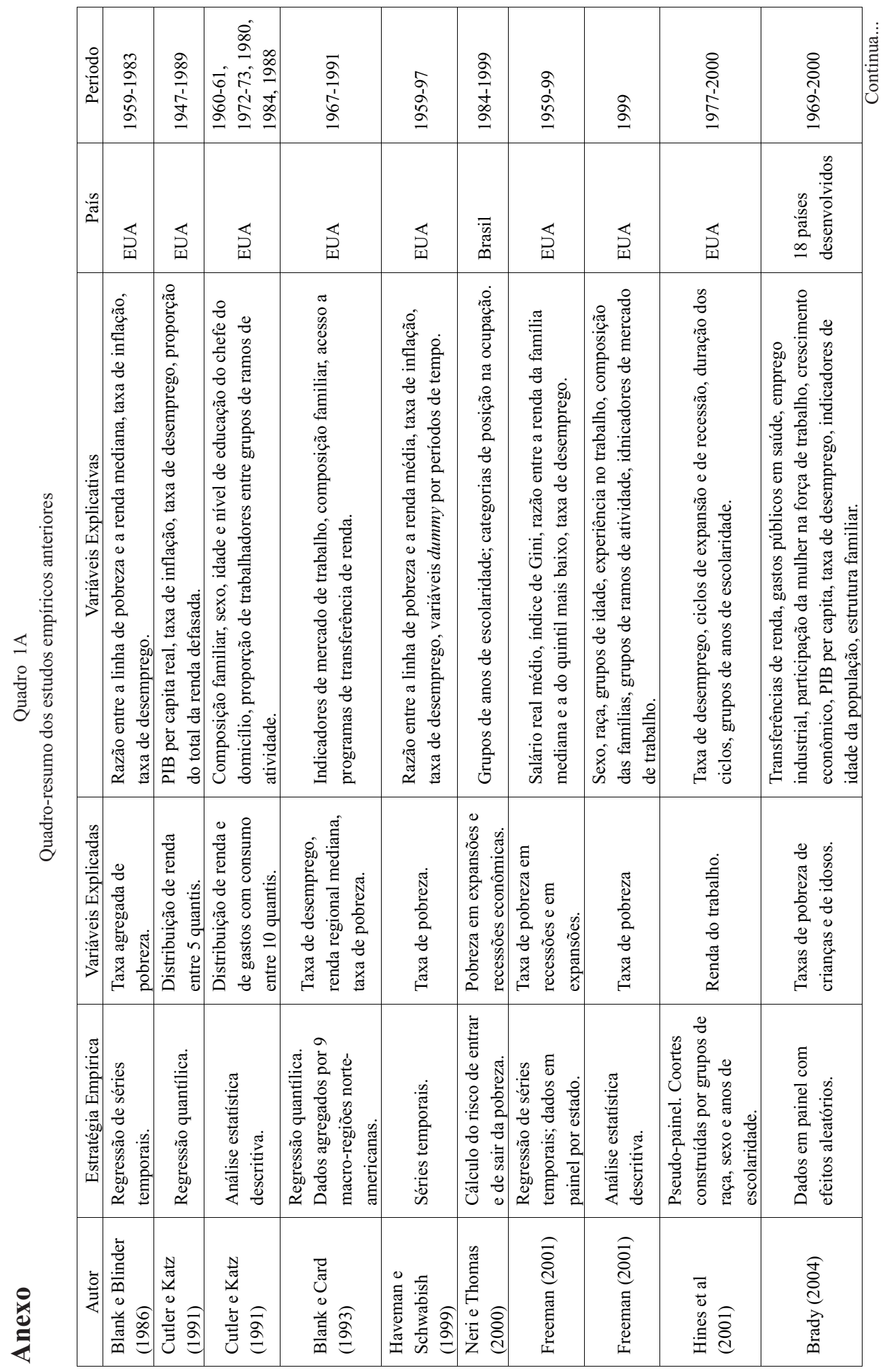


Ciclos econômicos e a composição da pobreza no Brasil

\begin{tabular}{|c|c|c|c|c|c|c|}
\hline 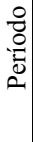 & $\begin{array}{l}8 \\
\stackrel{\circ}{1} \\
\frac{1}{2} \\
\frac{1}{2}\end{array}$ & $\begin{array}{l}a \\
\hat{i} \\
a \\
a\end{array}$ & $\begin{array}{l}\overline{0} \\
\stackrel{1}{1} \\
\infty \\
\infty \\
0\end{array}$ & 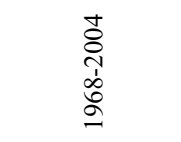 & 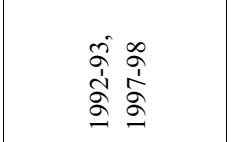 & 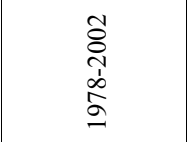 \\
\hline 公 & $\begin{array}{l}\bar{B} \\
0 \\
0 \\
0 \\
: \overline{0} \\
00 \\
0\end{array}$ & 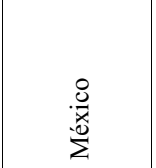 & 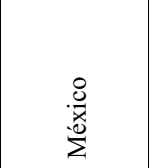 & 贫 & 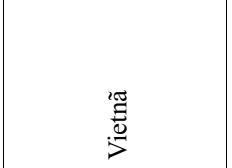 & $\begin{array}{l}\overline{\bar{n}} \\
\bar{n}\end{array}$ \\
\hline 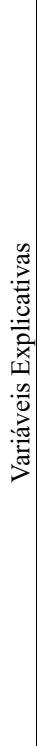 & 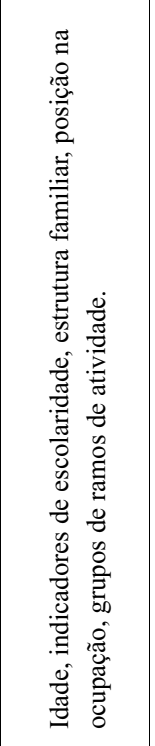 & 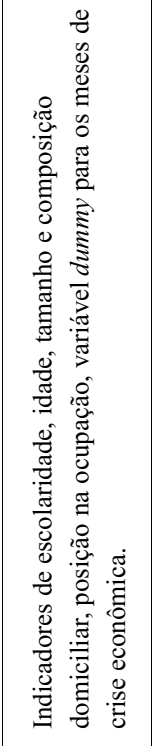 & 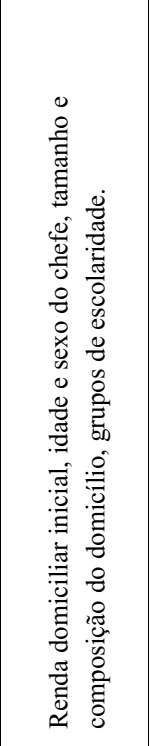 & 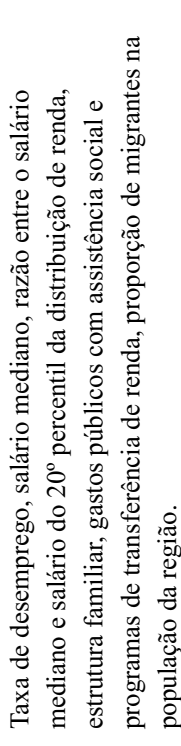 & 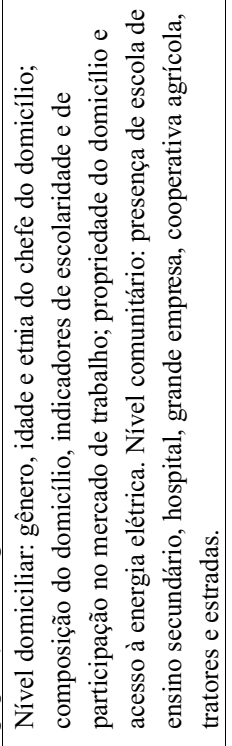 & 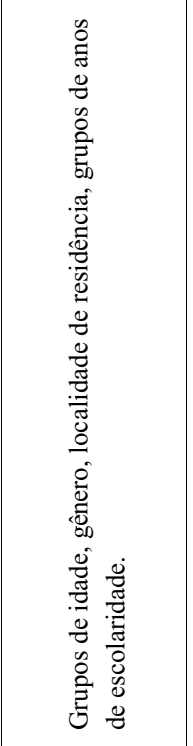 \\
\hline 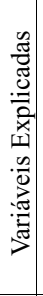 & 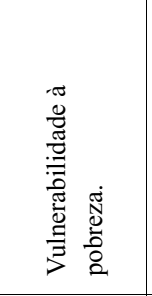 & 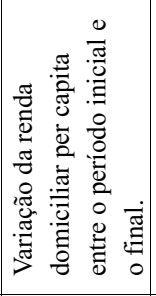 & 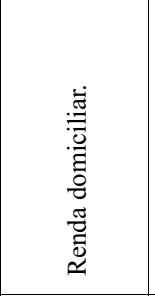 & 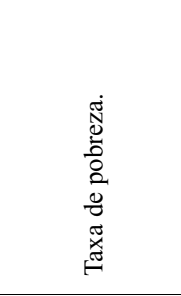 & 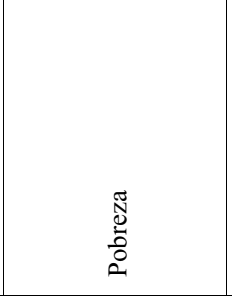 & 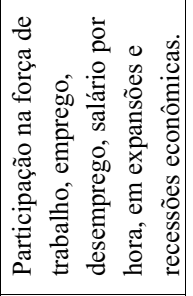 \\
\hline 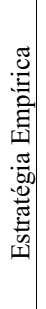 & 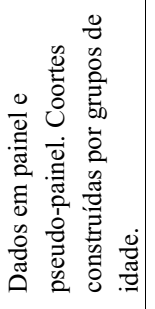 & 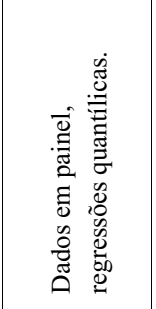 & 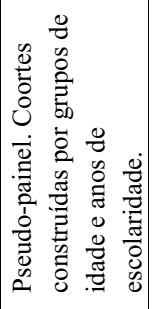 & 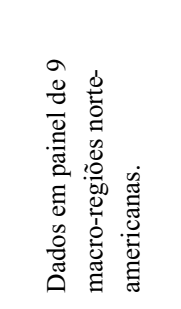 & 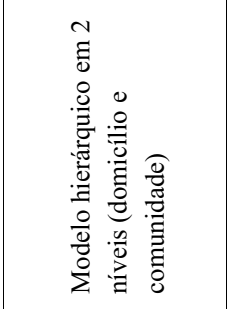 & 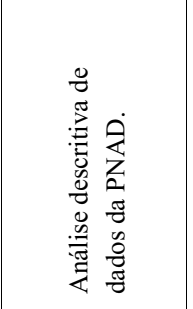 \\
\hline 妾 & 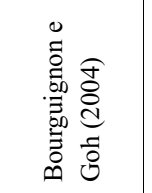 & 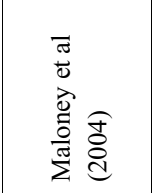 & 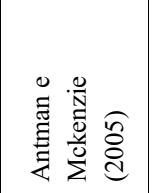 & 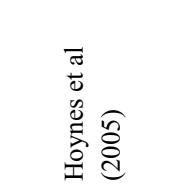 & 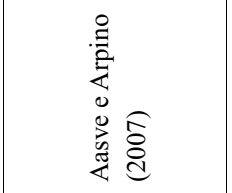 & 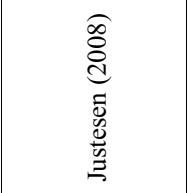 \\
\hline
\end{tabular}


Ricardo Agostini Martini / Ana Maria Hermeto / Frederico G. Jayme Jr.

Quadro 2A

Linha de pobreza por Unidade da Federação a preços de 2006

\begin{tabular}{|l|l||l|c|}
\hline Unidade da Federação & Valor & Unidade da Federação & Valor \\
\hline Acre & $\mathrm{R} \$ 176,18$ & Pará & $\mathrm{R} \$ 173,99$ \\
\hline Alagoas & $\mathrm{R} \$ 165,48$ & Paraíba & $\mathrm{R} \$ 167,23$ \\
\hline Amapá & $\mathrm{R} \$ 176,18$ & Paraná & $\mathrm{R} \$ 168,69$ \\
\hline Amazonas & $\mathrm{R} \$ 176,18$ & Pernambuco & $\mathrm{R} \$ 179,27$ \\
\hline Bahia & $\mathrm{R} \$ 169,48$ & Piauí & $\mathrm{R} \$ 164,22$ \\
\hline Ceará & $\mathrm{R} \$ 159,23$ & Rio de Janeiro & $\mathrm{R} \$ 183,42$ \\
\hline Distrito Federal & $\mathrm{R} \$ 165,75$ & Rio Grande do Norte & $\mathrm{R} \$ 166,40$ \\
\hline Espírito Santo & $\mathrm{R} \$ 130,94$ & Rio Grande do Sul & $\mathrm{R} \$ 182,31$ \\
\hline Goias/Tocantins & $\mathrm{R} \$ 155,56$ & Rondônia & $\mathrm{R} \$ 176,18$ \\
\hline Maranhão & $\mathrm{R} \$ 165,38$ & Roraima & $\mathrm{R} \$ 176,18$ \\
\hline Mato Grosso & $\mathrm{R} \$ 138,51$ & Santa Catarina & $\mathrm{R} \$ 165,43$ \\
\hline Mato Grosso do Sul & $\mathrm{R} \$ 139,91$ & São Paulo & $\mathrm{R} \$ 179,63$ \\
\hline Minas Gerais & $\mathrm{R} \$ 135,28$ & Sergipe & $\mathrm{R} \$ 168,35$ \\
\hline
\end{tabular}

Fonte: Elaboração própria tendo como referência a metodologia de construção de linha de pobreza apresentada pelo Instituto de Estudos do Trabalho e Sociedade (IETS), desenvolvida por Sônia Rocha. Disponível em: www.iets.gov.br.

Tabela 1A

Resultados dos modelos de regressão logística de pobreza

\begin{tabular}{|c|c|c|c|c|c|c|}
\hline Variável & Modelo 1 & Modelo 2 & Modelo 3 & Modelo 4 & Modelo 5 & Modelo 6 \\
\hline \multirow{2}{*}{ Informal } & & $0.334 * * *$ & $0.338 * * *$ & $0.341 * * *$ & $0.339 * * *$ & $0.340 * * *$ \\
\hline & & $(0.010)$ & $(0.010)$ & $(0.010)$ & $(0.010)$ & $(0.010)$ \\
\hline \multirow{2}{*}{ Integral } & & $-0.584 * * *$ & $-0.582 * * *$ & $-0.574 * * *$ & $-0.582 * * *$ & $-0.580 * * *$ \\
\hline & & $(0.009)$ & $(0.010)$ & $(0.010)$ & $(0.010)$ & $(0.010)$ \\
\hline \multirow{2}{*}{ Técnico } & & $-1.011^{* * *}$ & $-0.971 * * *$ & $-0.971 * * *$ & $-0.942 * * *$ & $-0.980 * * *$ \\
\hline & & $(0.028)$ & $(0.028)$ & $(0.028)$ & $(0.028)$ & $(0.027)$ \\
\hline \multirow{2}{*}{ Administrador } & & $-1.193 * * *$ & $-1.058 * * *$ & $-1.049 * * *$ & $-1.132 * * *$ & $-1.131 * * *$ \\
\hline & & $(0.049)$ & $(0.050)$ & $(0.051)$ & $(0.050)$ & $(0.050)$ \\
\hline \multirow{2}{*}{ Agropecuária } & & $-0.740 * * *$ & $-0.693 * * *$ & $-0.718 * * *$ & $-0.670 * * *$ & $-0.731^{* * *}$ \\
\hline & & $(0.026)$ & $(0.026)$ & $(0.026)$ & $(0.026)$ & $(0.026)$ \\
\hline \multirow{2}{*}{ Indústria } & & $-0.746 * * *$ & $-0.704 * * *$ & $-0.723 * * *$ & $-0.675 * * *$ & $-0.734 * * *$ \\
\hline & & $(0.029)$ & $(0.029)$ & $(0.029)$ & $(0.029)$ & $(0.029)$ \\
\hline \multirow{2}{*}{ Comércio } & & $-0.198 * * *$ & $-0.202 * * *$ & $-0.191 * * *$ & $-0.199 * * *$ & $-0.176 * * *$ \\
\hline & & $(0.010)$ & $(0.010)$ & $(0.010)$ & $(0.010)$ & $(0.010)$ \\
\hline \multirow{2}{*}{ Transportes } & & $-0.195 * * *$ & $-0.189 * * *$ & $-0.192 * * *$ & $-0.182 * * *$ & $-0.193^{* * *}$ \\
\hline & & $(0.016)$ & $(0.016)$ & $(0.016)$ & $(0.016)$ & $(0.016)$ \\
\hline \multirow{2}{*}{ Serviços } & & $0.437 * * *$ & $0.444 * * *$ & $0.444 * * *$ & $0.446 * * *$ & $0.452 * * *$ \\
\hline & & $(0.014)$ & $(0.014)$ & $(0.014)$ & $(0.014)$ & $(0.014)$ \\
\hline \multirow{2}{*}{ Empregador } & & $-0.445 * * *$ & $-0.451 * * *$ & $-0.442 * * *$ & $-0.444 * * *$ & $-0.416^{* * *}$ \\
\hline & & $(0.021)$ & $(0.021)$ & $(0.021)$ & $(0.021)$ & $(0.022)$ \\
\hline \multirow{2}{*}{ Mulher } & & $-0.050 * * *$ & $-0.049 * * *$ & $-0.050 * * *$ & $-0.048 * * *$ & $-0.052^{* * *}$ \\
\hline & & $(0.006)$ & $(0.006)$ & $(0.007)$ & $(0.006)$ & $(0.007)$ \\
\hline \multirow{2}{*}{ Negro } & & $0.353^{* * *}$ & 0.360 *** & $0.357 * * *$ & $0.397 * * *$ & $0.347^{* * *}$ \\
\hline & & $(0.008)$ & $(0.010)$ & $(0.010)$ & $(0.015)$ & $(0.015)$ \\
\hline
\end{tabular}


Tabela $1 \mathrm{~A}$ - Continuação

\begin{tabular}{|c|c|c|c|c|c|c|}
\hline Variável & Modelo 1 & Modelo 2 & Modelo 3 & Modelo 4 & Modelo 5 & Modelo 6 \\
\hline \multirow{2}{*}{ Urbano } & & $-0.605^{* * *}$ & $-0.610 * * *$ & $-0.627 * * *$ & $-0.615^{* * *}$ & $-0.629 * * *$ \\
\hline & & $(0.015)$ & $(0.015)$ & $(0.015)$ & $(0.015)$ & $(0.015)$ \\
\hline \multirow{2}{*}{ Tamanho da família } & & $0.268 * * *$ & $0.270 * * *$ & $0.272 * * *$ & $0.269 * * *$ & $0.271^{* * *}$ \\
\hline & & $(0.003)$ & $(0.003)$ & $(0.003)$ & $(0.003)$ & $(0.003)$ \\
\hline \multirow{2}{*}{ Chefe mulher } & & $0.053 * * *$ & $0.062 * * *$ & $0.059 * * *$ & $0.085^{* * *}$ & $0.037 * *$ \\
\hline & & $(0.010)$ & $(0.012)$ & $(0.012)$ & $(0.018)$ & $(0.018)$ \\
\hline \multirow{2}{*}{ Norte } & & $0.832 * * *$ & $0.837 * * *$ & $0.839 * * *$ & $0.844 * * *$ & $0.839 * * *$ \\
\hline & & $(0.036)$ & $(0.036)$ & $(0.036)$ & $(0.036)$ & $(0.036)$ \\
\hline \multirow{2}{*}{ Nordeste } & & $1.238 * * *$ & $1.242 * * *$ & $1.249 * * *$ & $1.244^{* * *}$ & $1.255^{* * *}$ \\
\hline & & $(0.033)$ & $(0.033)$ & $(0.033)$ & $(0.032)$ & $(0.032)$ \\
\hline \multirow{2}{*}{ Sudeste } & & $0.058^{*}$ & $0.058 *$ & $0.056^{*}$ & $0.055^{*}$ & $0.054^{*}$ \\
\hline & & $(0.033)$ & $(0.033)$ & $(0.032)$ & $(0.032)$ & $(0.032)$ \\
\hline \multirow{2}{*}{ Sul } & & $0.339 * * *$ & $0.338 * * *$ & $0.337 * * *$ & $0.333^{* * *}$ & $0.330 * * *$ \\
\hline & & $(0.035)$ & $(0.035)$ & $(0.035)$ & $(0.034)$ & $(0.034)$ \\
\hline \multirow{2}{*}{ Centro-oeste } & & 0.024 & 0.022 & 0.021 & 0.020 & 0.020 \\
\hline & & $(0.035)$ & $(0.035)$ & $(0.035)$ & $(0.035)$ & $(0.035)$ \\
\hline \multirow{2}{*}{ Coorte 1933-35 } & & $-0.093^{* * *}$ & $-0.276 * * *$ & $-0.306^{* * *}$ & $-0.207 * * *$ & $-0.304 * * *$ \\
\hline & & $(0.034)$ & $(0.034)$ & $(0.036)$ & $(0.034)$ & $(0.036)$ \\
\hline \multirow{2}{*}{ Coorte 1936-38 } & & $-0.213^{* * *}$ & $-0.460 * * *$ & $-0.377 * * *$ & $-0.341 * * *$ & $-0.372 * * *$ \\
\hline & & $(0.032)$ & $(0.033)$ & $(0.040)$ & $(0.032)$ & $(0.040)$ \\
\hline \multirow{2}{*}{ Coorte 1939-41 } & & $-0.222 * * *$ & $-0.523 * * *$ & $-0.364 * * *$ & $-0.384 * * *$ & $-0.358 * * *$ \\
\hline & & $(0.032)$ & $(0.033)$ & $(0.047)$ & $(0.032)$ & $(0.047)$ \\
\hline \multirow{2}{*}{ Coorte 1942-44 } & & $-0.289 * * *$ & $-0.631 * * *$ & $-0.449 * * *$ & $-0.461 * * *$ & $-0.443 * * *$ \\
\hline & & $(0.033)$ & $(0.034)$ & $(0.055)$ & $(0.032)$ & $(0.055)$ \\
\hline \multirow{2}{*}{ Coorte 1945-47 } & & $-0.291 * * *$ & $-0.665 * * *$ & $-0.436 * * *$ & $-0.446 * * *$ & $-0.429 * * *$ \\
\hline & & $(0.033)$ & $(0.036)$ & $(0.064)$ & $(0.033)$ & $(0.064)$ \\
\hline \multirow{2}{*}{ Coorte 1948-50 } & & $-0.259 * * *$ & $-0.683 * * *$ & $-0.408 * * *$ & $-0.424 * * *$ & $-0.402 * * *$ \\
\hline & & $(0.035)$ & $(0.038)$ & $(0.074)$ & $(0.035)$ & $(0.074)$ \\
\hline \multirow{2}{*}{ Coorte 1951-53 } & & $-0.193^{* * *}$ & $-0.662 * * *$ & $-0.342^{* * *}$ & $-0.362 * * *$ & $-0.335 * * *$ \\
\hline & & $(0.036)$ & $(0.040)$ & $(0.084)$ & $(0.036)$ & $(0.084)$ \\
\hline \multirow{2}{*}{ Coorte 1954-56 } & & $-0.123 * * *$ & $-0.638 * * *$ & $-0.272 * * *$ & $-0.298 * * *$ & $-0.266 * * *$ \\
\hline & & $(0.038)$ & $(0.043)$ & $(0.094)$ & $(0.038)$ & $(0.094)$ \\
\hline \multirow{2}{*}{ Coorte 1957-59 } & & -0.048 & $-0.603 * * *$ & -0.194 & $-0.222 * * *$ & $-0.188^{*}$ \\
\hline & & $(0.040)$ & $(0.046)$ & $(0.104)$ & $(0.040)$ & $(0.104)$ \\
\hline \multirow{2}{*}{ Coorte 1960-62 } & & 0.030 & $-0.563 * * *$ & -0.112 & $-0.141^{* * *}$ & $-0.106^{*}$ \\
\hline & & $(0.041)$ & $(0.048)$ & $(0.114)$ & $(0.041)$ & $(0.114)$ \\
\hline \multirow{2}{*}{ Coorte 1963-65 } & & $0.137 * * *$ & $-0.535 * * *$ & -0.038 & -0.060 & -0.034 \\
\hline & & $(0.043)$ & $(0.051)$ & $(0.124)$ & $(0.043)$ & $(0.124)$ \\
\hline \multirow{2}{*}{ Coorte 1966-68 } & & $0.189 * * *$ & $-0.502 * * *$ & 0.026 & -0.010 & 0.030 \\
\hline & & $(0.045)$ & $(0.054)$ & $(0.135)$ & $(0.045)$ & $(0.135)$ \\
\hline \multirow{2}{*}{ Coorte 1969-71 } & & $0.153 * * *$ & $-0.558 * * *$ & 0.087 & -0.017 & 0.092 \\
\hline & & $(0.046)$ & $(0.057)$ & $(0.146)$ & $(0.046)$ & $(0.145)$ \\
\hline Coorte 1972-74 & & $0.270 * * *$ & $-0.461 * * *$ & 0.165 & $0.103^{* *}$ & 0.170 \\
\hline Coorte 19/2-/4 & & $(0.048)$ & $(0.059)$ & $(0.156)$ & $(0.048)$ & $(0.156)$ \\
\hline Coorto 197577 & & $0.438 * * *$ & $-0.317 * * *$ & $0.276^{*}$ & $0.336 * * *$ & $0.281^{*}$ \\
\hline coorte 19/3-/1 & & $(0.050)$ & $(0.063)$ & $(0.167)$ & $(0.050)$ & $(0.166)$ \\
\hline & & $0.366 * * *$ & $-0.423 * * *$ & $0.295 *$ & $0.348 * * *$ & 0.281 \\
\hline 78-80 & & $(0.053)$ & $(0.068)$ & $(0.178)$ & $(0.054)$ & $(0.178)$ \\
\hline N. Obs. & 985669 & 983278 & 983278 & 983278 & 983278 & 983278 \\
\hline
\end{tabular}

*** Variável significativa a 1\%; ** Variável Significativa a 5\%; * Variável Significativa a 10\% Fonte: Elaboração própria a partir de dados da PNAD. 